\title{
Examining the influence of indicator variables on crowding and visitor experience: A case study of the White Salmon River in Washington
}

\author{
Candace L. Weaver \\ West Virginia University
}

Follow this and additional works at: https://researchrepository.wvu.edu/etd

\footnotetext{
Recommended Citation

Weaver, Candace L., "Examining the influence of indicator variables on crowding and visitor experience: A case study of the White Salmon River in Washington" (2010). Graduate Theses, Dissertations, and Problem Reports. 4670.

https://researchrepository.wvu.edu/etd/4670

This Thesis is protected by copyright and/or related rights. It has been brought to you by the The Research Repository @ WVU with permission from the rights-holder(s). You are free to use this Thesis in any way that is permitted by the copyright and related rights legislation that applies to your use. For other uses you must obtain permission from the rights-holder(s) directly, unless additional rights are indicated by a Creative Commons license in the record and/ or on the work itself. This Thesis has been accepted for inclusion in WVU Graduate Theses, Dissertations, and Problem Reports collection by an authorized administrator of The Research Repository @ WVU. For more information, please contact researchrepository@mail.wvu.edu.
} 
Examining the Influence of Indicator Variables on Crowding and Visitor Experience:

A Case Study of the White Salmon River in Washington

\title{
Candace L. Weaver
}

Thesis submitted to the

Davis College of Agriculture, Natural Resources \& Design

at West Virginia University

in partial fulfillment of the requirements

for the degree of

Master of Science

in

Recreation, Parks, and Tourism Resources

\author{
Robert Burns, Ph.D., Chair \\ Steve Selin, Ph.D. \\ David Smaldone, Ph.D.
}

\section{Recreation, Parks, and Tourism Resources Program \\ Division of Forestry and Natural Resources}

\section{Morgantown, West Virginia \\ 2010}

Keywords: Social Carrying Capacity, Whitewater, Use levels, Social Impacts, Visitor experience 


\section{ABSTRACT \\ Examining the Influence of Indicator Variables on Crowding and Visitor Experience: A Case Study of the White Salmon River in Washington.}

\section{Candace L. Weaver}

The purpose of this study was to assess social carrying capacity on the White Salmon River. The study chose a series of evaluative standards and indicator variables to test the relationship between possible predictors and feelings of crowding for river users. The study also sought to discover any relationships between the user's feelings of crowding and overall visitor satisfaction. Interviews and surveys were conducted during the summer of 2009 onsite at the three possible White Salmon River whitewater exit points. The findings were analyzed using SPSS statistical software. It was found that river users were very satisfied with their river experience and were not crowded. Several indicators and evaluative standards were found to significantly affect the social atmosphere for river users. 


\section{Acknowledgements}

First and foremost I would like to thank my thesis committee and the Recreation, Parks and Tourism Faculty for their assistance and guidance while I completed graduate school. I would specifically like to thank Dr. Robert Burns and Jennifer Wade for giving me the opportunity to collect data on the White Salmon. I learned so much from my experience and will use the guidance they have given me as I move into the work force.

I would also like to thank Chad Pierskalla for all his guidance and help he gave me on my Journey through graduate school and Brett Haggerty for allowing me to have such a fantastic job. Thank you to Stacy and Maddy for always being there to keep me going and keeping me laughing even under extreme stress. I would like to extend a special thank you to Sandy for her time helping me grasp SPSS and data analysis, I truly appreciate it.

Finally I would like to thank my Mom and Dad for their support through all of my education and life endeavors as well as getting me outside in the first place. Finally I would like to thank Kris and all my friends for their love and support while I finished up at WVU! Thank you all! 


\section{TABLE OF CONTENTS}

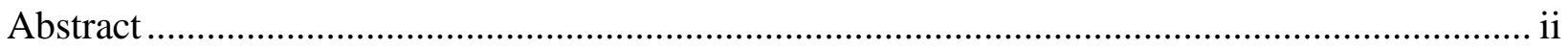

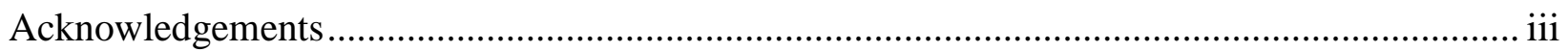

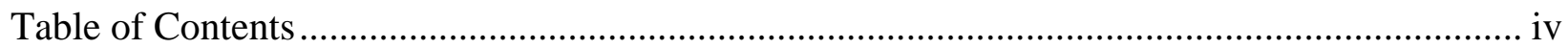

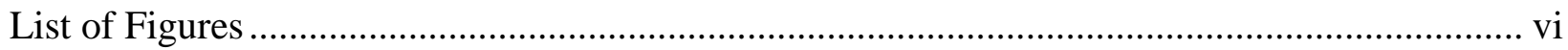

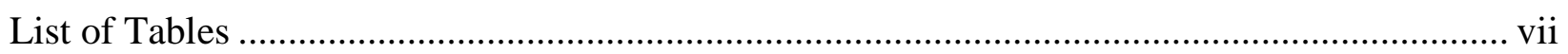

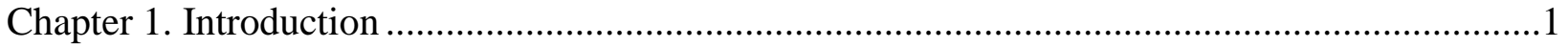

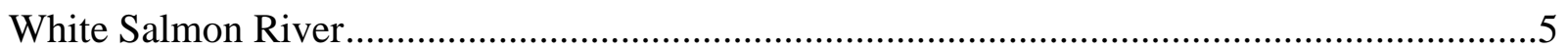

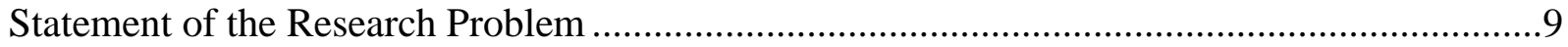

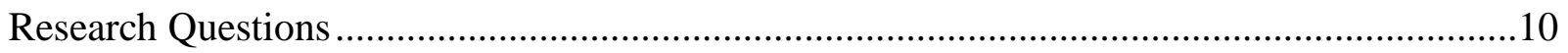

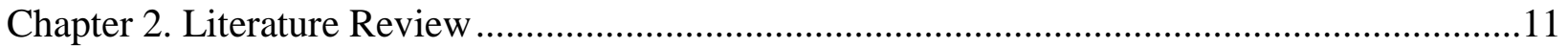

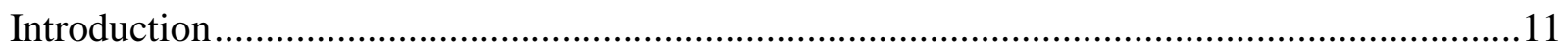

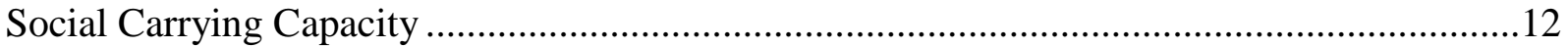

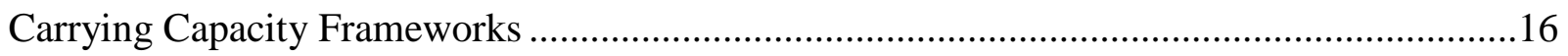

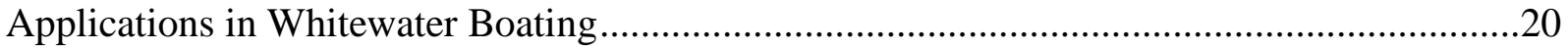

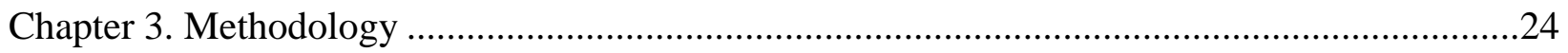

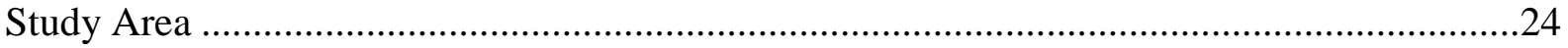

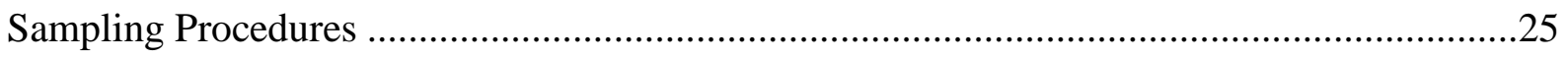

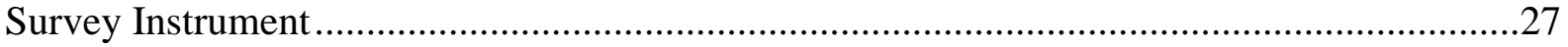

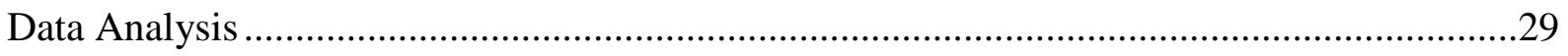


Chapter 4. Results

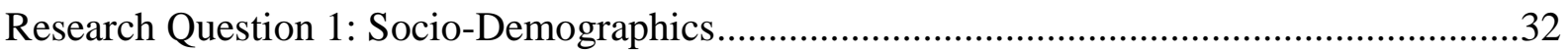

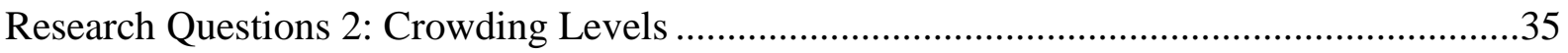

Research Question 3: Indicator Variables and Crowding Levels ........................................39

Research Question 4: Crowding and Indicators and Overall Trip Satisfaction ......................41

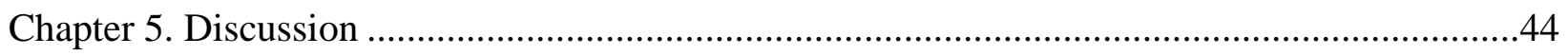

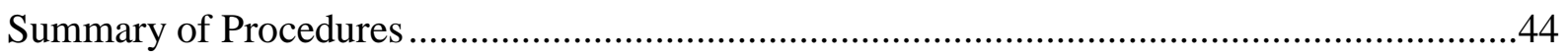

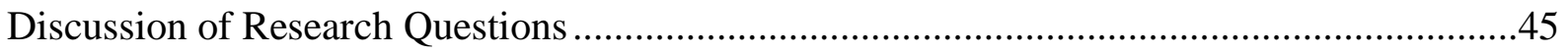

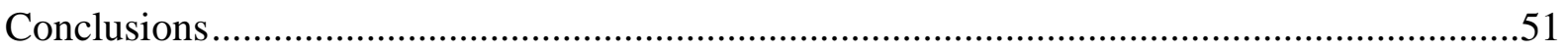

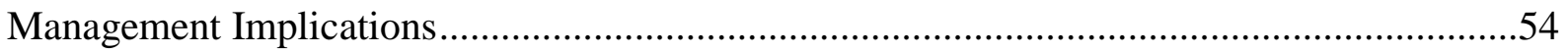

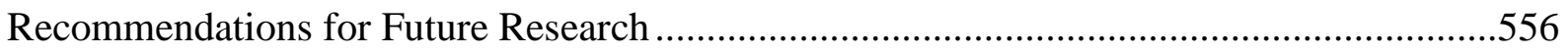

Appendices

Appendix A

White Salmon River User Survey .................................................................5

Appendix B

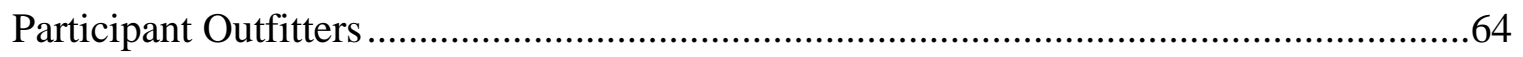

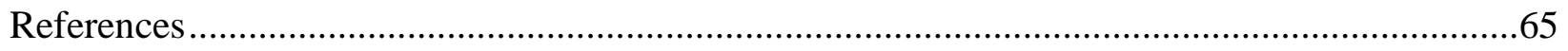




\section{LIST OF FIGURES}

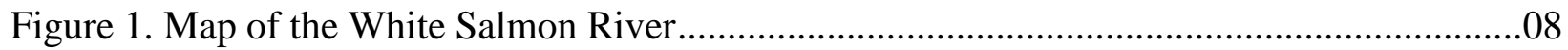

Figure 2. Limits of Acceptable Change (LAC) .................................................................. 18

Figure 3. Visitor Experience and Resource Protection (VERP) ...........................................19

Figure 4. Visitor Impact Management (VIM) ................................................................20

Figure 5. Model of Crowding Predictors and Feelings of Crowding ......................................43 


\section{LIST OF TABLES}

Table 1. Battery of Crowding Indicator Variables............................................................29

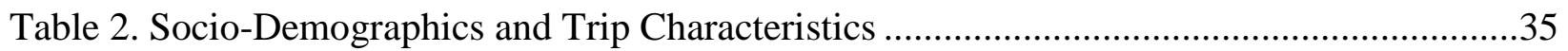

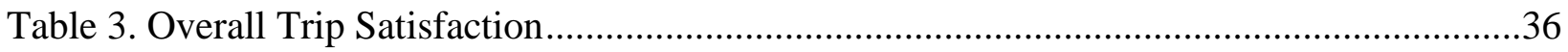

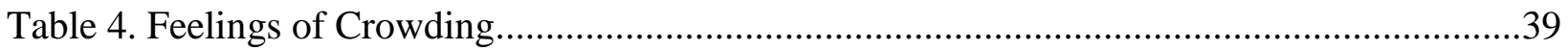

Table 5. Feelings of Crowding for Independent Variables .................................................40

Table 6. Results of Anova Table for Feelings of Crowding ...................................................41

Table 7. Multiple Regression Analysis of Crowding variables with Feelings of crowding ..........42

Table 8. Pearsons R Correlations for Crowding Indicator Variables ......................................43

Table 9. Multiple Regression Analysis of Feelings of crowding and indicator variables with

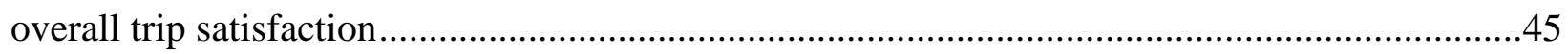

Table 10. Pearsons R Correlations for Crowding Indicator Variables and Trip Satisfaction........45 


\section{CHAPTER 1}

\section{INTRODUCTION}

Since the middle of the 1960's, participation in and the demand for outdoor adventure recreation has been growing in the United States, especially in recent years (Buckley, 2007). People throughout the country are looking for new ways to invigorate their bodies and minds while experiencing the outdoors (Buckly, 2007; Ewert, 1997; 2000; Nielson \& Shelby, 1976; Shelby \& Heberlein, 1986). Traditional outdoor recreation activities such as hiking, biking and camping are still widely enjoyed, but there has been an increasing trend in the demand for adventure recreation (Ewert, 2000). One of the most notable adventure activities receiving attention is whitewater boating. The growth of participation in this river based sport has lead to an increase in the need for quality and efficient management practices (Boteler, 1984; Brunson, Shelby \& Johnson, 1992; Shelby \& Heberlein, 1986; Tarrant \& English \& English, 1996).

Whitewater rafting and kayaking first became popular in the late 1960's and early 1970s (Boteler, 1984; Brunson et al., 1992; Shelby \& Heberlein, 1986; Tarrant \& English, 1996). Since its initial upsurge, participation in the sport has remained steady and in recent years has again seen increases in whitewater kayaking (Cordell, 2008). There are several reasons that can attempt to explain the recent and expected continual rise in participation in whitewater boating. According to Ewert, a variety of technological advancement has made it easier and safer to engage in whitewater activities. These advancements include synthetic clothing and materials, self-bailing rafts, playboats, radio towers and cellular phones (Ewert, 2000). Ewert also suggested that television and radio commercials and programs have allowed the activity, usually 
thought to be dangerous, to be portrayed in a fun and safe manner to a mass public audience. Buckley (2007) suggests that the general commercialization of adventure sports has also added to the increase. Whatever the reason, this increase in popularity has led management officials and researchers to be concerned about the future use of the rivers for whitewater recreation.

As the use of rivers for whitewater recreation expands, so does the need for management and possible regulation. Over use of a river can adversely affect the biological and social aspects of the resource (Boteler, 1984; Manning, 2007; Shelby \& Heberlein, 1986; Tarrant \& EnglishStrother \& Vogelsong, 2003; Tarrant \& English \& English, 1996). A common use issue that has been the subject of both past and recent research is the concept of social carrying capacity. Social carrying capacity refers to the amount of users that can be accommodated at a given site or area without negatively affecting the biological environment or the visitor experience (Manning, 2000, 2007; Shelby \& Heberlein, 1986; Shelby \& Johnson, 1992). Social carrying capacity is used throughout the recreation field as a framework for combating crowding and resource deterioration in recreation settings. Management is an important factor in effectively managing carrying capacity to ensure that standards are being maintained (Manning, 2007; Rae \& Eagles, 2007). There are four types of capacities that are each focused on a specific impact: ecological, social, physical and facility (Manning, 2007; Shelby \& Heberlein, 1986).

Carrying capacity was originally used in wildlife management for finding the number of animals that an area could comfortably sustain without negative impacts. Currently the framework is used in a variety of recreational settings by a wide array of different managers and agencies (Manning, 2007; Manning \& Lime, 1996; Shelby \& Heberlein, 1986). This study focuses on social carrying capacity. 
There are various social impacts that are associated with increasing visitor use in outdoor recreation. Crowding is often considered by researchers to be one of the dominant social impacts related to a rise in use levels (Manning, 2007; Manning \& Lime, 1996). The term crowding refers to a negative evaluation about a specific density or number of encounters while recreating (Manning, 2007; Manning \& Lime; 1996). Density and crowding, while similar, are not the same. Density is a descriptive standard and refers to the number of people per unit area, while crowding is more of a personal preference or individual judgment on the density of people (Manning, 2007; Manning \& Lime, 1996; Manning, Valliere, Minteer, Wang \& Jacobi, 2000; Shelby \& Heberlein, 1986). The concept of crowding is often studied from a normative perspective that is based in an individual's personal beliefs and standards about appropriate amount of visitor use or contact levels while involved in outdoor recreation (Manning, 2007; Manning \& Lime, 1996). Though crowding is thought to affect overall visitor satisfaction, some research suggests that the relationship between crowding and satisfaction is of low significance (Manning, 2007; Manning \& Lime, 1996, 2000; Shelby \& Heberlein, 1986). Closely related to crowding is the idea of conflict among users and user groups. Conflict is found mostly between different types of user groups and often comes into play in whitewater recreation between commercial and private boaters (Boteler, 1984; Shelby \& Heberlein, 1986).

Essentially, social carrying capacity relates to the quality of the visitor experience. Visitor experience or visitor satisfaction is said to be significantly degraded by social impacts such as crowding, conflict, use levels and so on (Strother \& Vogelsong 2002). Research has begun looking at this phenomenon in depth. There are several models and approaches to carrying capacity currently used in research, which are designed to analyze and relate these social impacts to the visitor experience. 
Various frameworks are currently used in addressing the issue of carrying capacity. The Limits of Acceptable Change (LAC) model was originally designed to assist national parks and wilderness protected areas that were having issues with degradation and failure. It focuses on discovering what conditions are appropriate for a location or site, and how to attain those desired conditions instead of just asking "how much is too much?" (McCool, 1996; Manning, 2007; Stankey, Cole, Lucas, Petersen, \& Frissell, 1985). The Visitor Experience and Resource Protection (VERP), used by the National Park Service (NPS), looks at a prescription of desired social and ecological conditions as well as what the visitor deems appropriate (Manning \& Lime, 1996).

Visitor Impact Management (VIM) was designed by researchers working for the National Park Conservation Association (NPCA) for use by the National Park Service (NPS). VIM is similar to the other frameworks above but it includes an extra step that involves looking at the causes associated with the defined impacts in order to prescribe appropriate management tactics (Graefe, Kuss \& Vaske, 1990; Hsu, Li \& Chuang 2007; Nilsen \& Taylor, 1997).

The frameworks described above are all used in social carrying capacity research. According to Manning and Lime (1996) and Manning (2007), these models all include several of the same descriptive steps: Desired future conditions, identification of indicators of quality experiences and resources conditions and monitoring management practices. While these frameworks are widely used throughout the outdoor recreation field, this study is focused on social carrying capacity in whitewater boating.

Research into whitewater river social carrying capacity dates back as far as the 1970s. In 1979, Shelby \& Colvin conducted a use level and capacity study on the Rogue River in Oregon. The study was done in order to understand Rogue River use levels and possible impacts from 
increases in use level (Shelby \& Colvin, 1979; Shelby \& Heberlein, 1986). Similarly, a river contact study was conducted in the Grand Canyon to address use, regulation and permit systems in 1975 (Shelby \& Neilson, 1976). Since these initial studies, many have been performed all over the United States to address the growing industry of whitewater boating. Tarrant \& English (1996) created a framework for carrying capacity use on the Nantahala River in North Carolina, where he found that regulations should be put into place in order to reduce social impacts on the visitor experience. Similar studies have been conducted in Pennsylvania and Maryland on the Youghiogheny River and also in West Virginia on the Cheat, New and Gauley Rivers (Graefe, Gitelson, Fedler, \& Zeigler, 1989; Whisman, 1998).

It is important that whitewater boating use be studied in order to protect the rivers and the experience of those who come to enjoy them. This social carrying capacity research can be used in aiding managers and policy makers in decision making processes related to use level regulation and application. The research these studies provide can help understand the expectations of the users and help guide managers into making conditions on the rivers acceptable to those who use them.

\section{White Salmon River}

The White Salmon River is located in southern Washington State. It is a tributary to the Columbia River and is also considered to be part of the Columbia River Gorge National Scenic Area. The section of the White Salmon River examined in this study is also protected under the Wild and Scenic Rivers Act. The White Salmon River is a popular river run for Portland and Coastal areas, and also draws visitors from all over the country and from around the world.

The White Salmon River provides recreation opportunities for everyone from whitewater novice to advanced boaters. The whitewater rivers of the United States are rated on a scale of 1- 
5, where 1 is the easiest and 5 is extremely difficult (American Whitewater Association, 1998). Rivers are described as being class I through class $\mathrm{V}$, using Roman numerals as the numbering system. According to the American Whitewater Association, who adapted the international rating scale to the United States, class I rivers are consider easy with small riffles with a low chance of accidentally falling out of the boat. Class II rapids are considered to be for the novice boater with some maneuvering required and a low chance of accidental swimming. Class III is considered intermediate and requires some maneuvering that can be challenging. Injuries are rare in class III but safety should be setup and inexperienced parties should use caution. Class IV rapids are for advanced boaters and contain intense and powerful rapids that can often require a paddler to move around dangerous obstacles and water features. Injury during accidental swims is considered to be moderate to high with rescuing becoming difficult. Finally, class V is for experts. These rapids are long, violent and contain big drops and large water features that make accidental swimming very dangerous and rescuing very difficult. Even experienced boaters should exercise extreme caution (AWA, 2010).

Using the class I-V classification system, the White Salmon River is a continuous class III experience, meaning it is mostly intermediate, but there is a class V waterfall drop located in Husum, WA. Husum is located about half way down the commercially navigable section of the River. This waterfall is for advanced boaters and can be portaged or avoided fairly easily. The river is mostly surrounded by private land and also has high canyon walls for a large portion of the run. There are three main launch areas and river exit points for the river. BZ Corner, maintained by the U.S. Forest Service, is the most common place for boaters and rafters to begin their whitewater trip. At this location, all boaters must fill out a registration form and deposit it into a locked Forest Service registration box. These registration cards include information such 
as group leader name, commercial or private, number of people in party and location the party plans to exit the river. Boaters who launch at the BZ Corner put-in raft the more difficult class III and V sections.

The Husum Falls area is the second exit located onthe class III (V) section. This area also serves as a put-in for the Lower section of the White Salmon River, which is a mostly class II run. The area directly surrounding the falls is maintained by the U.S. Forest Service. The remainder of the land surrounding the river is private. Two of the eight companies that run the White Salmon River officially take out at this location on private land. It is possible for boaters to portage, or walk around Husum Falls (class V) and continue down the Lower White Salmon River by lining boats down the waterfall or carrying boats around it on the roadway.

The final exit location is the Buck Creek exit point and park, owned by Pacific Power and Light Company. There is a dam one mile downstream of the Buck Creek take-out that creates a small lake where the water slows and rafters and kayakers can make an easy and safe exit from the river. This location is also used for picnicking, small motor boats, and various other recreation activities. Several commercial companies use this park as their meeting place and lunch spot for rafting trips. Figure 1 shows a map of the White Salmon River with appropriate launch and exit points. 
Figure 1

Map of the White Salmon River

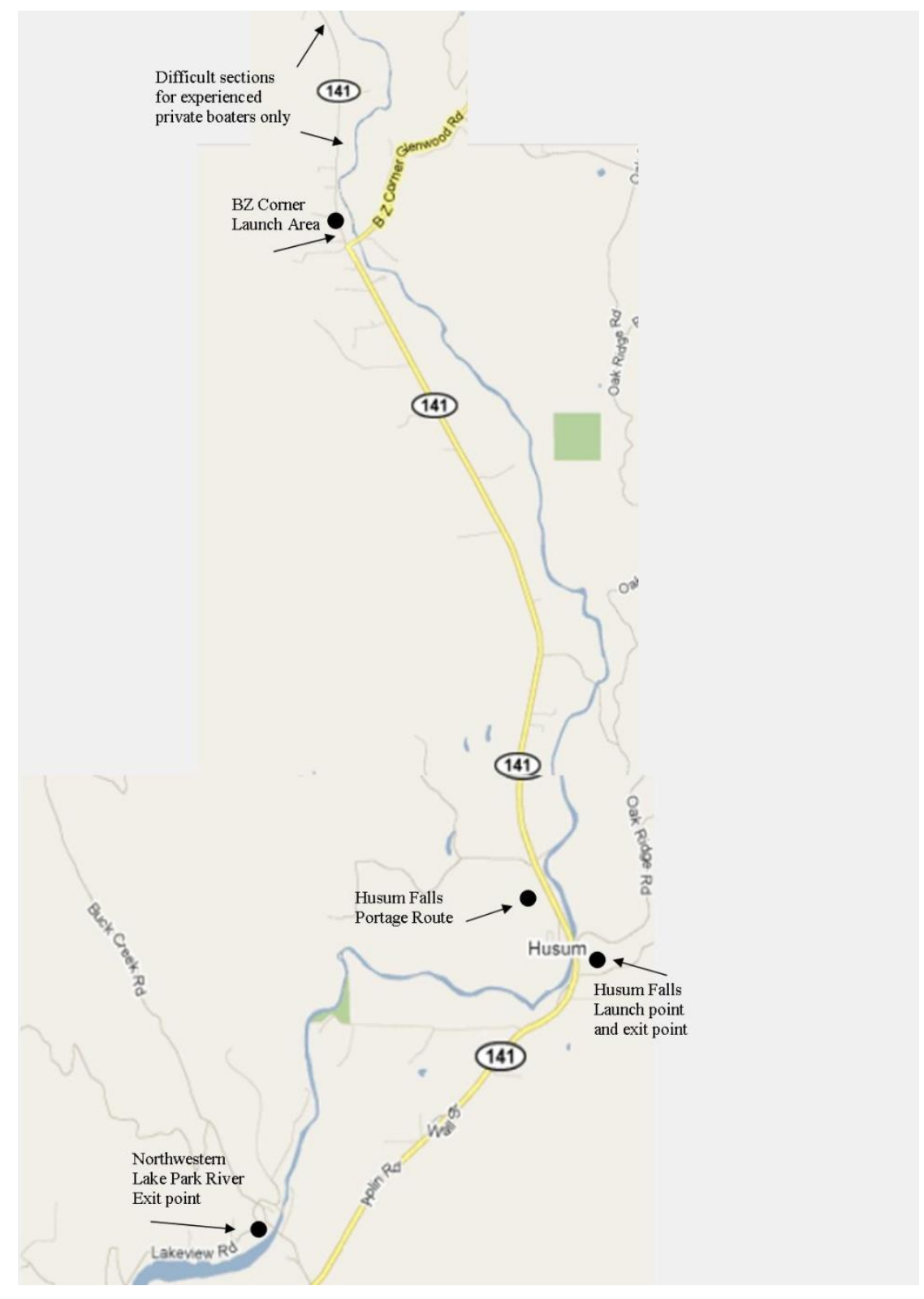

A comparison of two separate studies shows a dramatic increase in use levels on the White Salmon River (Allen \& Ratcliffe, 1988; Burns Graefe \& Wade, 2008). Both studies found that crowding increased slightly but was not significantly affecting satisfaction levels for river users. The pilot study was fairly short and only touched on surface issues. A full-scale study was needed in order to properly and efficiently analyze crowding and other social impacts on the White Salmon River. 
Currently there are nine commercial permits available to outfitters, one of which has been suspended. One of the permits is also allotted to a fishing outfitter. For years the commercial outfitters have self-regulated launch times with very little conflict. Companies work together in relative harmony at river entry and exit locations. This is generally not the case with other rivers where it is common for management to step in and control outfitters with regulation. Every ten years at the White Salmon River, the US Forest Service, who controls the permits for Wild and Scenic Rivers and National Scenic Areas, must reassess the permitting process to decide if capacity has been exceeded, and if the river users are experiencing social impacts related to overuse. The state of Washington has also implemented a special use permitting system that requires an analysis of use to decide how to handle special permits for river use. In order to properly decide on a permit system and regulations for whitewater boating on the White Salmon River, research was needed to understand the social impacts on the river.

\section{Statement of the Research Problem}

The primary purpose of this study is to investigate social carrying capacity on the White Salmon River in Washington. It will test the relationship of quality indicators such as crowding, encounters, wait time, group size, and conflict on the overall visitor trip experience. Understanding the social impacts associated with whitewater boating is important for managers to consider when creating policies or use limitations. Like many other rivers, the White Salmon River has seen a significant increase in use since the 1990s, making it important that use level regulation be re-evaluated. A pilot study done on the White Salmon River in 2008 found use has dramatically increased and that crowding increased slightly. While users were found to be highly satisfied, researchers suggest that the findings should be evaluated against standards (Burns et al., 2008). 
This study is part of a larger scale effort that will be used to aid U.S. Forest Service management decisions regarding outfitter guide permits and river capacities. The U.S. Forest Service will be the sole decision maker for management applications. This study is the social carrying capacity portion of the larger research effort that will also include research on physical carrying capacity and environmental carrying capacity.

\section{Research Questions}

$\mathrm{R}_{1:}$ What does the sample of recreationists look like?

$\mathrm{R}_{2}$ : What is the crowding level on the White Salmon River?

$R_{2 A}$ : There is no significant difference based on gender.

$\mathrm{R}_{2 \mathrm{~B} \text { : }}$ There is no significant difference based on age.

$\mathrm{R}_{2 \mathrm{C} \text { : }}$ There is no significant difference based on whether the visitor was a first time visitor or a returning visitor.

$\mathrm{R}_{2 \mathrm{~d}}$ : There is no significant difference based on group type (commercial or private).

$\mathrm{R}_{3}$ : Are the crowding indicator variables (wait time, group size, and number of others seen) effective predictors of crowding levels?

$\mathrm{R}_{4}$ : Are crowding and crowding indicators effective predictors of overall trip satisfaction. 


\section{CHAPTER 2}

\section{LITERATURE REVIEW}

The purpose of this section is to review relevant literature related to social carrying capacity, quality indicators, crowding, conflict and carrying capacity frameworks, followed by its application to whitewater boating.

\section{Introduction}

Whitewater boating, in all forms, has become one of the fastest growing human-powered outdoor activities in the United States (Presidents' Commission on the Outdoors, 1987; Bowers \& Hoffman, 1999). Several researchers have found that there has been a slight increase in the popularity of kayaking and canoeing since the 1960s (Buckley, 2007; Cordell, 2008; Cordell et al., 1999; Ewert 2000). In recent years both kayaking and canoeing have seen a large increase in the number of users, and are considered to be one of the fastest growing nature-based activities in the United States (Cordell, 2008). On the other hand, whitewater rafting has seen steady to moderate decreases in the amount of people participating (Cordell, 2008). It is more common for first time boaters to be commercial users (Rae \& Eagles, 2007) who do not know what to expect from the river trip (Manning, 2007). Lastly, whitewater boating is attractive to all ages and sexes because it is based on skills and technique rather than on strength (Bowers \& Hoffman, 1999).

Though kayaking and rafting are enjoyed by people of all ages (Cordell, 2008), the most popular age for these whitewater activities are those between the ages 25-49. This group encompassed $71 \%$ of the kayaking population, $55.5 \%$ of the rafting population and $49.4 \%$ of the canoeing populations. The second age group was those aged $16-24$ with $22.5 \%$ of kayakers and $37.1 \%$ of rafters falling into this category (Cordell et al., 1999). 
As the popularity of kayaking and canoeing grows, and whitewater rafting participation continues, the possible impacts associated with this increase in use are becoming a great concern (Hsu et al., 2007; Manning, 2007; Manning et al., 1996; Manning et al., 2000; Rae \& Eagles, 2007; \& Heberlein, 1986; Stroler, 1996; Tseng et al., 2009). Often overcrowding can lead to use-regulations and quotas in order to maintain a standard of quality (Bowers \& Hoffman, 1999; Manning, 2000). Managers and officials are faced with decisions regarding the limiting of use and other restrictions in order to control impacts to both the environment and to the visitor experience. In order to make knowledgeable and fair decisions, social carrying capacity studies are being done in order to understand the use levels and thresholds for river usage. The overall goal is to balance the demand for river access and use while protecting the resource and the satisfaction of river users.

\section{Social Carrying Capacity}

The idea of carrying capacity first gained popularity within the wildlife management field, where it dealt with the amount of animals that could be sustained in a given habit before negative impacts were noted (Manning, 2001; 2007; Manning \& Lime; 1996; Shelby \& Heberlein, 1986; Strother \& Vogelsong, 2003; Wager, 1964). The researchers who originally recognized the relationship between nature impacts and the visitor, defined social carrying capacity as the level of recreational use an area can withstand while providing a quality of recreation, a quality environment and a quality recreational experience (Sterl, Wagner \& Arnberger, 2004; Wager, 1964). Below are descriptions of each of the four types of capacities as described by Shelby \& Heberlein. (1986, p, 19-21):

Ecological: impacts on the ecosystem

Social: social impacts, such as impacts that hinder or alter human experiences 
Physical: the actual amount of space for accommodating recreation

Facility: improvements for handling visitor needs (i.e parking lots, boat ramps and restrooms)

As interest in outdoor recreation increased, the need to apply carrying capacity as a means of understanding and limiting use in recreation areas and parks became apparent. The concept of carrying capacity was first utilized in recreation in the 1960s (Manning, et al., 2002).

In terms of recreation, Shelby and Heberlein (1986) explained that carrying capacity "is concerned with determining the number of users that can be accommodated by a given area without loss in the quality of the natural environment (biological carrying capacity) and/or the visitor experience (social carrying capacity)” (p. 19).

Social carrying capacity is the subject of intense research in the recreation field. Despite having impressive amounts of research dedicated to the subject, it is still seen as fairly undefinable, and efforts to determine and apply the concept have been met with frustration (Graefe \& Vaske, 1990; Manning, 2001, 2007 ;Manning \& Lime, 1996). Social carrying capacity is linked to the effects of over use of an area on the quality of the visitor experience (Manning, 1996; Manning \& Lime, 1996; Shelby \& Heberlein, 1986; Sterl et al., 2004). Shelby et al. (1986) explained that social carrying capacity refers to (social) impacts which impair or alter human experiences (visitor experience). According to Manning \& O'Dell (1997), the quality of the visitor experience degrades as the park resources degrade , and as crowding, conflict and other social impacts occur (Manning, 2007; Strother \& Vogelsong, 2003). Social carrying capacity is often difficult to determine because the basis for understanding the effects of social impacts on the visitor are based on evaluative standards (McCool, 1996; Manning, 2000; 2007; Manning \& Lime, 1996; Shelby \& Heberlein, 1986). 
Manning and Lime (1996) suggested that crowding is seen as the "most direct physical and psychological manifestation of the increasing trend in visitor use" (p. 29) and is generally considered by researchers to be one of the more prevailing social impacts related to rising visitation. Crowding is a more complex concept then most would imagine because it not only refers to numbers of people, but it also deals with the visitor's evaluation of that number. Crowding involves a value judgment and is a psychological perception with in the minds of individuals (Shelby \& Heberlein 1986). Several researchers suggest that crowding is closely linked and easily understood as a normative theory concept (Manning, 2000; Manning \& Lawson, 2002; Manning \& Lime 1996; Shelby \& Heberlein 1986; Tarrant \& English, 1996). Vigorous research has been conducted in order to combat the issues of increasing visitor use and crowding. Understanding the variables affecting visitor's perceptions of crowding is important when dealing with over use (Hsu et al. 2007; Tseng et al., 2009). Several variables are said to affect the relationship between visitor use and perceived crowding. These are often called evaluative indicators (Hsu et al., 2007; Manning, 2000; 2007; Shelby \& Heberlein, 1986).

The number of encounters users experience is closely linked to crowding and over use. The higher the number of human encounters a person has while recreating, the more likely they will feel crowded (Hsu et al., 2007; Manning, 2007; Manning et al., 2000; 2004; Manning \& Lime, 1996; Shelby \& Heberlein, 1986; Stankey et al., 1984; Tseng et al., 2009). The higher the use levels of an area, the higher the chance that more encounters will occur. Party or group size has also been suggested as a factor affecting crowding norms (Manning \& Lime, 1996). Stankey (1973) reported that visitors to a wilderness area indicated that they would prefer to encounter parties of five or smaller. Another experience that is thought to affect crowding and satisfaction is conflict (Hsu et al., 2007; Tseng et al., 2009). Conflict is related to an interference in 
satisfying a visitors goals within a recreation area, or "goal blocking" (Shelby \& Heberlein, 1986). Often when a person visits a wildland setting they have an idea of what to expect of their experience. However, when others interfere with this expectation or goal; it causes conflict (Hsu et al., 2007; Manning \& Lime, 1996; Manning, 2007; Shelby \& Heberlein, 1986). In summary, there can be a difference in what a visitor expects from their recreation experience and what they actually receive. This concept relates to satisfaction and the visitor experience. For example, Shelby and Heberlein (1986) found that those who entered an area expecting a wilderness setting felt more crowded by the same number of encounters then by someone who was expecting a semi-wilderness setting. This concept further explains how feelings of crowding are related to personal evaluative standards.

Satisfaction and use levels are another interesting topic studied within the carrying capacity. Research has found that as an evaluative standard, there is little relationship between contacts and satisfaction (Shelby \& Heberlein, 1996; Tseng et al., 2009). Researchers have offered explanations for this disconnect between satisfaction and encounters (Shelby \& Heberlein, 1996). The first is that recreation involves freedom of choice, so people have already chosen something they enjoy. It might be harder to affect their level of satisfaction because they are happy and have made the decision to engage in that activity; possibly already having an idea about what to expect. The second explanation has to do with product shift. Product shift has to do with expectation and coping behaviors. It has to do with the re-evaluation of the recreation activity. Shelby \& Heberlein (1986) supplied an example using the Grand Canyon. If a person begins a trail expecting wilderness and is met on the trail by several groups of people, the visitors has two choices; they can either be dissatisfied, or change their view of the resource to encompass these encounters. An example of this would be deciding that the area is not a 
wilderness trail but a semi-wilderness trail (Shelby \& Heberlein, 1986, p. 55). The final explanation is displacement, which involves the unsatisfied visitor searching for a lower-density recreation experience somewhere else (Manning \& Lime, 1996).

Manning and Lime (1986) used normative theory to explain these phenomena in a similar way. The three cognitive coping mechanisms used in this theory are site succession, product shift and rationalization. Site succession refers to the processing of a visitor's norms in reaction to the change in use levels at a site or area. In other words, as use increases the visitor just accepts the high use levels because they feel the rise was inevitable. Product shift is defined in the same manner as Shelby \& Heberlein (1986). The third coping mechanism is the process of rationalization (Manning \& Lime, 1996). This involves a similar framework to that of Shelby \& Heberlein's idea of free-choice. The user chose to be there so they will naturally want to be satisfied. This can cause the visitor to report higher satisfaction because they chose that activity.

\section{Carrying Capacity Frameworks}

Over the years, research has produced several frameworks for measuring and assessing carrying capacity in wilderness settings. One of the most popular and widely used frameworks is Limits of Acceptable Change (LAC). The LAC framework was created in response to increasing demands on recreational areas to assist managers in addressing the issue in a logical and visible fashion (Stankey et al., 1985). Unlike other capacity management strategies that focused on "how much is too much", the LAC framework attempts to answer "what resources and social conditions are appropriate (or acceptable), and how do we attain those conditions?" (Manning \& Lime, 1996). According to Manning (2000), this method seeks to discover how much crowding should be allowed, not alleviate crowding all together. Limits of acceptable changes is based upon eleven principles that stemmed from research into visitor impacts as well as growing 
demand from the public to be included in decision making for protected areas (McCool, 1996; Manning, 2007; Stankey et al., 1985). Those eleven principles include elements that require managers to create objectives, understand what and how visitors impact and expectations of an area as well as encourage input from many different user groups and stakeholders (McCool, 1996; Stankey et al., 1985).

Using these eleven principles, a systematic approach was created for assessing an area for its limit of acceptable change. The planning system used to implement the LAC process was originally composed of four components, but eventually grew to nine steps to ensure effective use of the framework (see figure 2). The goal is to form objectives, consider what you have and what is available, and then actively monitor any decisions that have been made.

Figure 2

Limits of Acceptable Change Framework

\section{Limits of Acceptable Change Planning System}

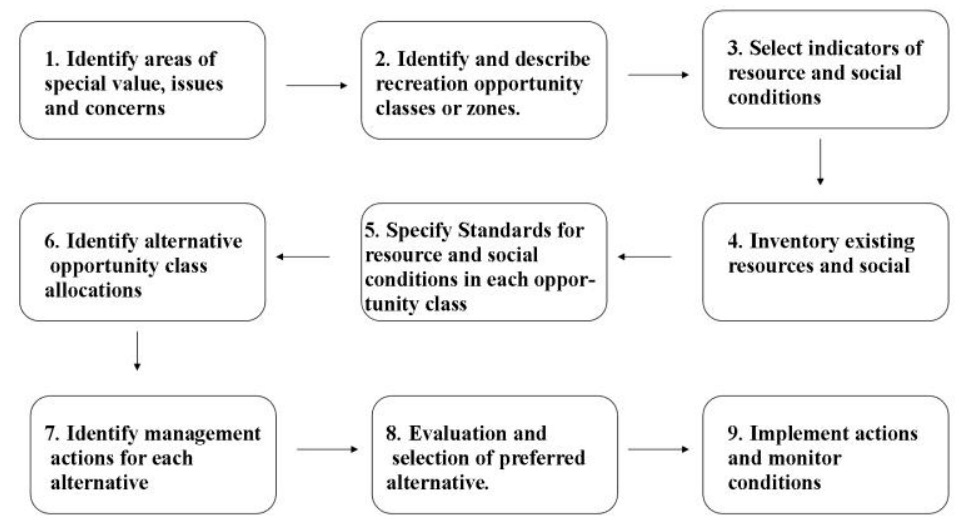

(McCool, 1996)

Visitor Experience and Resource Protection (VERP) is another framework used within the recreation field to help better manage visitors and use. This system is commonly used by the 
National Parks Service. VERP seeks to both protect the natural resource as well as the quality of the visitor experience. This model attributes possible threats to the quality of the visitor experience to visitor use levels, types of use, visitor behavior, timing of use, and location of use (Manning \& Lime, 1996). VERP is similar to LAC in that it is composed of nine elements that systematically organize management for both natural resource integrity and visitor experience (see figure 3). It involves selecting potential indicators of quality and then surveying visitors based on those indicators chosen (Manning, 1997). The VERP strategy, unlike the LAC, has a required public involvement step built in as its second element. It makes decisions based on what visitors find to be acceptable for their experience.

Figure 3

Visitor Experience and Resource Protection Framework

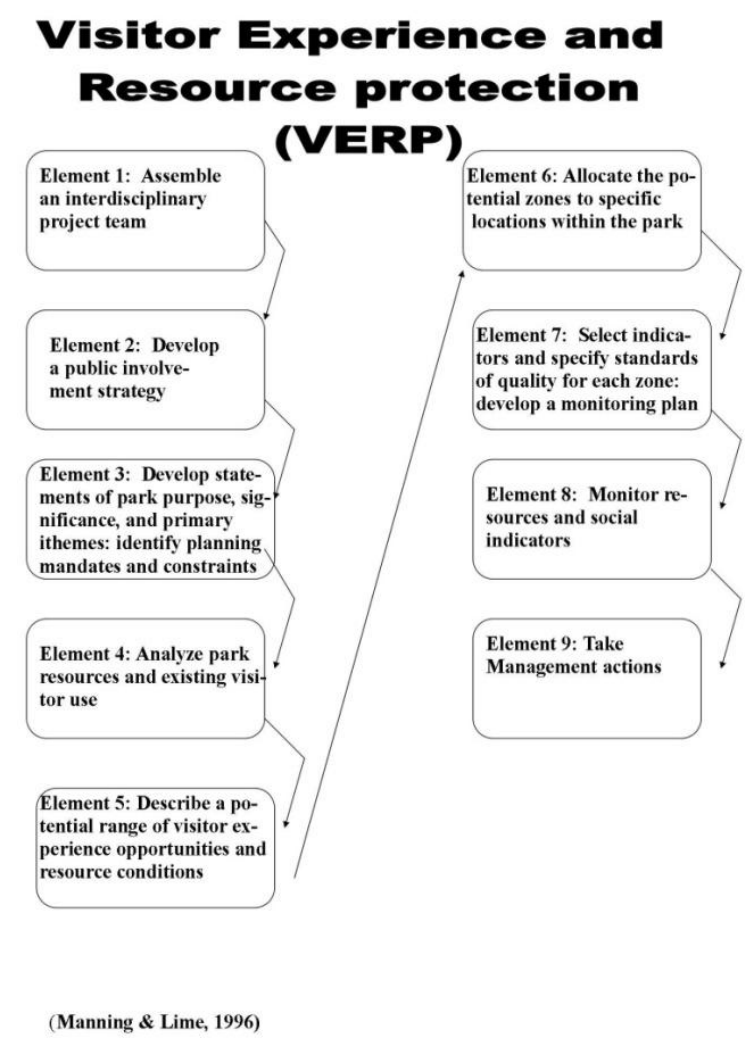

Another commonly used framework within the carrying capacity field is the Visitor Impact Management (VIM) model. This model follows a very similar setup and chronology to 
that of the LAC and VERP model but also has a specific step just to address precise issues and seeks to identify the causes for specific impacts (Graefe et al., 1990). The steps of the VIM framework can be seen in a figure created by Burns et al. (2008) to simplify the description of the process (Figure 4).

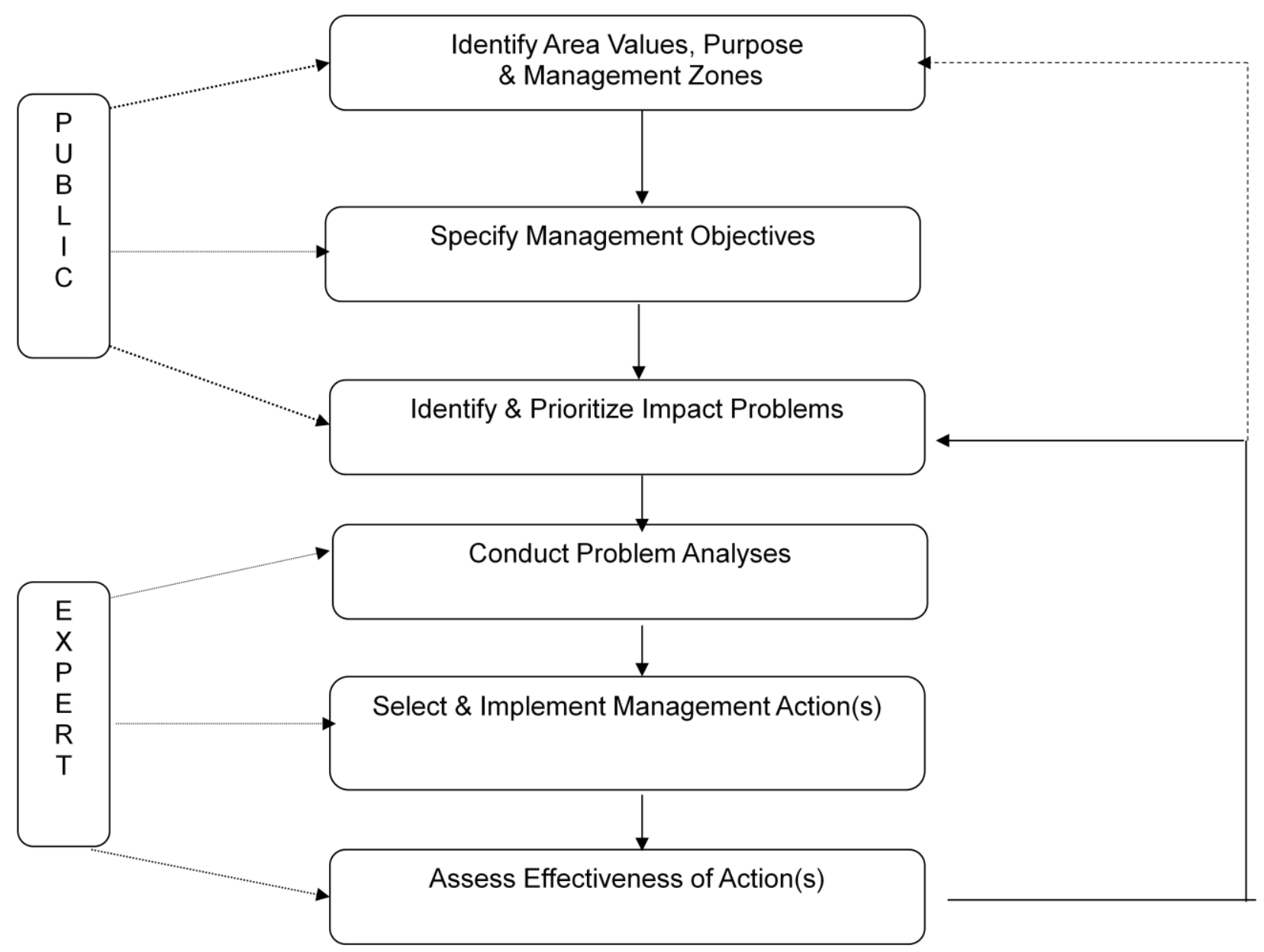

One of the important factors that can be found in each of these carrying capacity frameworks is the formulation of indicators and standards that can be used to assess crowding and use levels systematically. Manning (2000) describes indicators of quality as "specific measurable variables that reflect the essence of meaning of management objectives" (p. 31). 
These variables are quantifiable and can measure management objectives. Indicators can be related to both physical and social characteristics that are vital in defining the quality of the visitor experience (Manning, 2007). Indicators are chosen to reflect what conditions are believed to affect the visitor experience (Manning, 2000, 2007). It is also important that managers closely monitor the chosen standards of quality to be sure the quality is maintained. Researchers and managers can use indicators to find out whether or not standards of quality are being met. If managers seek to keep crowding under a three on a nine point scale, three would be considered the standard of quality. Once these standards have been met, capacity has been exceeded (Manning, 2000, 2007; Shelby \& Heberlein, 1986). Indicators can be different based on management objectives and specific sites.

\section{Social Carrying Capacity and Crowding: Applications in Whitewater Boating}

Social carrying capacity has been used to evaluate use levels on whitewater rivers since the 1970s (Boteler, 1984; Shelby \& Nielson, 1976; Shelby \& Heberlein, 1986). An important point to note about whitewater social carrying capacity is that often the visitors have not experienced the activity before, therefore they do not have any preconceived norms regarding the recreation setting or crowding. This can sometimes lead to higher satisfaction levels (Shelby \& Heberlein, 1986). Tarrant \& English (1996) pointed out that even in wilderness whitewater areas; fewer than $67 \%$ of participants have pre-conceived norms about encounters. River use management objectives often define the desired recreation opportunity to be provided and evaluative standards refer to acceptable levels of impact (Rae \& Eagles, 2007; Tarrant \& English, 1996, p. 2). The evaluative approach is often used in whitewater when measuring crowding. This idea uses a 9-point scale; where 1 is "not at all crowded" and 9 is "extremely crowded." The visitor chooses which number represents their feeling toward how crowded they 
were, using the 9-point Likert Scale (Shelby \& Heberlein, 1986). Another important note about social carrying capacities' application for river use is that agencies that manage rivers are able to visually see how recreation opportunity is connected to a range of acceptable use conditions (Tarrant \& English, 1996). River social carrying is often addressed in the form of regulations and use restrictions on use times and group size (Brunson et al., 1992).

One of the first studies conducted to establish river capacities for boaters was in 1975 on the Grand Canyon. Shelby \& Heberlein (1986) conducted a study in order to understand the impacts from the rising use levels. Over 1,000 river participants were surveyed over the summer of 1975 . The study looked at evaluative standards to determine if boaters were being negatively affected by social impacts, and if carrying capacity had been exceeded. Indicators used were encounters, party size, satisfaction, crowding (9-point scale), hours in sight of others, and number of stops with encounters (wait time). The study also asked participants what type of setting they perceived the river to be wilderness, semi-wilderness, or undeveloped recreation. It was found that as use levels increased on the Colorado River, perceived crowding among visitors did not. There was also no significant difference between use levels and satisfaction.

In a similar study done by Shelby and Nielson (1979) on the Rogue River in Oregon, the results turned out very different. The study found that users were experiencing up to 85 encounters a day. Social carrying capacity on the Rogue River had been exceeded. The researchers suggested that the 120 per day use limit on the Rogue River be lowered. Researchers also found that as use levels increased so did perceived crowding. Encounter norms were found to have exceeded every level of the setting descriptions (ie. Wilderness, semi-wilderness, and undeveloped). If current restrictions were kept the same, a change would have to occur in the 
type of experience the Rogue River provided. Spreading out the launch times and access points was also given as an alternative to lowering use numbers.

As the Rogue River example illustrates, social carrying capacity on rivers has become hard to define and even harder to apply, because it may be difficult to balance the demand for use and the acceptability of that use (Shelby \& Heberlein, 1986). Tarrant \& English (1996) conducted a study of boaters on the Nantahala River in North Carolina to develop a crowdingbased model that managers could use to help determine an acceptable range of carrying capacities for whitewater boating. On-site surveys were administered using a 9-point crowding scale (1-“not at all crowded, 9-“extremely crowded" with medium crowding in between). It assessed crowding levels against use levels and also crowding levels against CFS (amount of water flow in Cubic Feet per Second). The study found a range of available use limits. The first standard is the most restrictive. It allows for the amount of users scoring crowding below 3 on the 9-point scale to be no less than $35 \%$ of total river users. If the percentage of river users' ranking crowdedness above a 3 drops below 35\%, it would be unacceptable under this restriction. This would limit the amount of commercial use per day. The least restrictive ensures that no less than $20 \%$ of river users will choose a rating less than 3 , meaning that the percentage of visitors that rank crowding at a rating less than 3 can be no less than $20 \%$ of the total surveyed. This allows more use but may cause more people to feel crowded. The study did find a correlation between CFS and crowding. Higher water levels and faster flow allowed for higher use levels and less perceived crowding. Important notes about this model are that there is agreement between managers and visitors about the type of recreation opportunity to be provided and that the evaluative standards are valid indicators of crowding. This builds on the previous research by Shelby \& Colvin (1979), on the Rogue River and Colorado River in that it omits the 
need for the 2 point crowding threshold (on the 9 point scale) allowing for more variation in the nature of the resource (Tarrant \& English, 1996).

In 1988, Allen and Ratcliffe conducted a use study on the White Salmon River. Their objectives were to determine the amount and type of use in the scenic area, develop a list of issues and concerns from both commercial and non-commercial boaters, and to create an inventory of the river's existing and potential access and public use areas. Researchers found that river use had significantly increased over the course of the 1980s, having the most use between June and August. It was also found that around $70 \%$ of boaters were commercial users and only $30 \%$ were non-commercial (private) users. Those who were surveyed were encouraged to comment. The largest concerns were that the river would be over permitted or access would be taken away. Allen and Ratcliffe (1988) also found only minor conflicts between private and commercial rivers users. Private rafters suggested more restrictions and use limits on commercial trips and group sizes. Overall the study found that river use was increasing over the years.

As the river use on the White Salmon River increases, it will be important for managers and outfitters to understand their users as well as the social impacts that are being created by current use levels. By implementing social carrying capacity frameworks and using evaluative standards, this study assessed the White Salmon River use and its associated impacts. Having a clear understanding of possible evaluative indicators such as crowding levels, encounters, trip characteristics, expectations and visitor satisfaction will enable the Forest Service to make informed decisions about the future of whitewater recreation on the White Salmon River. 


\section{CHAPTER 3}

\section{METHODOLOGY}

\section{Study Area}

Research for this study was conducted in and around the White Salmon River in Washington. The White Salmon River is a tributary to the Columbia River which meanders between the states of Oregon and Washington. The eight mile section of whitewater used in this study, which runs from above BZ Corner to Buck Creek, is currently considered to be part of the Columbia River Gorge National Scenic Area and is part of the Wild and Scenic Rivers system. The river enters the Columbia River just west of White Salmon, Washington and across the gorge from Hood River, Oregon. The river is fed mostly by underground springs breaking to the surface as well as glacier run off from Mount Adams. It is one of the only commercially boated Whitewater Rivers that has consistent water flow all summer long.

The area included in this study was the White Salmon River, which has three exit or takeout points along its shores; Above BZ corners down to BZ corner, BZ corner to Husum, or to a community park outside Buck Creek. Both BZ corner and Husum Falls are used as both a river exit point and launch points for the White Salmon River. The launch area in BZ corner is monitored and maintained by the U.S. Forest Service and a camp host is onsite to supervise the self-permitting system. Husum falls is a private take-out and exit point. There are typically only two commercial outfitters who use this take out area as well as many private boaters. The river exit point at Buck Creek is maintained by the Pacific Power and Light Company and is open to the public for use. 
The section located between BZ Corner and Husum is considered to be a solid class III whitewater run with a ten foot waterfall drop called Husum Falls. The waterfall drop is only recommended for experienced boaters and guided customers. The section below the Husum waterfall to the Buck Creek exit point is a class II-III run that becomes easier as you continue down river. In the early part of the season, water levels become too high to run Husum Falls. Many boaters choose to portage the falls and continue to Buck Creek or exit the river in Husum without going over the waterfall.

While several outfitters posts are located between BZ Corner and Buck Creek, many are from other areas, such as Hood River and Maupin, Oregon as well as several towns outside Seattle, Washington. Participants are representative of a variety of local outfitters' customers and private boaters who run the White Salmon River. Currently outfitters self-regulate in an organized and harmonious fashion. The nine outfitters have created a system that functions well on its own, but the Forest Service needs to be sure that river capacities are not being exceeded.

\section{Sampling Procedures}

This is a quantitative study. Interviews were conducted from June 6, 2009 to September 13, 2009 on the White Salmon River in Washington. Participants were asked to complete surveys at the conclusion of the whitewater trip. Interviews were completed on the shuttle bus ride from the take-out in Husum to the put-in at BZ Corner. Other interviews were completed at one of three locations: BZ corner, Husum Falls area, or Buck Creek. Some survey participants were boating on the Green Truss section which uses BZ Corner as a river exit point. This section is for very advanced boaters so there was only a small portion from this user group. Depending on expected use levels, there were one to two surveyors per day. 
One surveyor was stationed at the Buck Creek Park, where they approached recreationists on the trips that were exiting the river. Some respondents were given a clipboard and pencil and asked to fill out their survey on the way to back to the outfitters station on the bus. If there was a break, or if use levels were low, the interviewer followed the bus back to the outfitter post in order to be available for questions or issues with the survey. There were also private boaters and commercial customers who finished their river trip and stayed at the lake. These respondents were asked to take a few minutes to fill out the survey onsite. In these cases, surveys were conducted in an interview fashion where the surveyor read each question to the respondent and recorded the answers onto the survey. If a potential respondent refused the face-to-face interview they were asked to complete their survey on their own time and return it to the surveyor when they finished.

The second surveyor was stationed at the Husum Falls launch and river exit area. This interviewer rotated between outfitter stores and private boaters who were parked in the Husum parking area or along the roadways. Most surveys completed at this survey site were conducted as face-to-face interviews where the surveyor asked and recorded answers onto the survey form. Surveying at Husum required walking up and down the river bank to catch those who exit the river above Husum Falls and those who exit the river below. This survey point generally experienced a lower use rate than Buck Creek. This surveyor, on low use days or during later hours, travelled to the BZ Corner launch and exit point to try to locate boaters who boated the more difficult section above. This method was not preformed often because of the lower use rate found on the upper sections of river. 


\section{Survey Instrument}

The survey consisted of questions from a variety of areas expected to affect crowding such as group size, encounters, group type, and trip characteristics (Table 1). The analysis tested whether crowding indicators were good predictors of overall crowding as well as what the influence of crowding, conflict and evaluative indicators have on the overall visitor trip experience. A 9-point crowding scale was used to gather feelings of crowding information where 1 equaled "not at all crowded" and 9 was "extremely crowded", middle scores of "slightly crowded" and "moderately crowded" appeared in the middle section of the scale.
1
$2 \quad 3$
4
5
6
7
8
9

Not at all Crowded Slightly Crowded $\quad$ Moderately Crowded $\quad$ Extremely Crowded

Two of the four questions were based on encounters or how many people were seen while recreating. These questions involved percentage scales that ranged from $0 \%-100 \%$, where customers were asked to pick a percentage pertaining to the amount of encounters they experienced on the river. The two remaining encounter questions asked participants to fill in specific numbers: these questions are the primary focus of this study. Overall trip experience was rated on a 6-point scale ranging from: poor, fair, good, very good, excellent or perfect.

Overall, how would you rate your trip today? Poor Fair, it just didn't work out very well Good, but I wish a number of things could have been different Very good, but it could have been better Excellent, only minor problems Perfect 
To determine which group size was preferred, respondents were asked to choose from a bank of group sizes, and select the option that best describes their preference. The four choices respondents were given were: small (5 people or less), medium (6-15 people), large (16-25 people) and it doesn't matter. All other questions were either open-ended or involved writing in a specific number or number of minutes.

A similar survey instrument was used in a pilot study on the White Salmon River in 2008. Questions regarding the date and time of the trip and a few socio-demographic questions were added in order to gather data on visitor demographics. The survey used in this study is being used in a larger study to assess attributes and issues pertaining to whitewater river social carrying capacity. A similar survey is being used in several wilderness and recreation areas throughout the United States in order to create a system for measuring social carrying capacity in a number of different settings. Due to the length and depth of the survey used, this thesis only assessed specific questions pertaining to conflict and indicators of crowding that were expected to be found on the White Salmon River. Questions that were not expected to pertain to the White Salmon River were omitted. Evaluative standards that were found to be significant in previous research efforts were used to analyze crowding and its possible predictors on the White Salmon River (Graefe et al., 1984; Manning, 2000; Manning \& Lime, 1996; Stankey et al., 1973,2004; Shelby \& Heberlein 1986; Strober et al., 2004; Wager, 1969). 
Table 1

Battery of crowding indicator variables

\begin{tabular}{|c|c|}
\hline Type & Question \\
\hline \multicolumn{2}{|l|}{ Encounters } \\
\hline & Percent of time in sight of other boats \\
\hline & How many times saw other boats from other groups \\
\hline & Number of times OK to see others \\
\hline & Percent of time OK to be in sight of others \\
\hline \multicolumn{2}{|l|}{ Conflict } \\
\hline & Did you experience a social conflict? \\
\hline \multicolumn{2}{|l|}{ Wait time } \\
\hline & Wait time at the start of your trip \\
\hline & Ok amount of time to wait at the start \\
\hline \multicolumn{2}{|l|}{ Expectations } \\
\hline & Actual vs. expected encounters (also an encounter question) \\
\hline & Experience that should be provided \\
\hline \multicolumn{2}{|l|}{ Trip } \\
\hline \multicolumn{2}{|l|}{ Characteristics } \\
\hline & Trip Type (Commercial or Private) \\
\hline & How far in advance trip planned (Year, month, day or hours) \\
\hline & Trip Length (Day or overnight) \\
\hline & Date of trip \\
\hline & Time of trip start \\
\hline & Group Size \\
\hline & Preferred Group Size \\
\hline & First Visit? (Visitor Status) \\
\hline
\end{tabular}

\section{Data Analysis}

This study made use of quantitative analysis because the content analyzed was based on counting encounters or users, volumes, and associations between entities. In other words, this study was based on systematic scales and numbers (Gelo, Braakmann, \& Benetka, 2008). According to Gelo et al. (2008), "Quantitative research requires the reduction of phenomena to numerical values in order to carry out statistical analysis" (p. 268). This study sought to attain a 
general idea of the feelings and experiences based on numerical scales and write in numerical answers of the users of the eight mile section of the White Salmon River.

The following section discusses the methods used to analyze and examine data for each research question. All of the research questions were analyzed using the statistical analysis software SPSS v. 16.

$R_{1}$ : What does the sample of recreationists look like?

A total of seven socio-demographic and trip characteristic questions were used to create a profile of White Salmon River respondents. Overall satisfaction is reported here because it is an integral part of the profile for river users. Frequencies and valid percents were reported in order to examine the following socio-demographics and trip characteristics: age, gender, trip type, group size, international visitors, group type, and first time visitor.

$R_{2}:$ What is the crowding level on the White Salmon River?

To find crowding levels for the White Salmon Visitors, both frequencies and valid percents were analyzed and examined. Crowding levels were reported by visitors using the 9point crowding scale created by Shelby and Heberlein (1986).

$\mathrm{R}_{2 A}$ : There is no significant difference based on gender.

A test to compare the mean crowding scores for gender was used because gender is a categorical variable.

$R_{2 B}$ : There is no significant difference based on age.

Age is a quantitative variable, so a One-way ANOVA test was performed in order to analyze age against reported crowding scores.

$R_{2 C:}$ There is no significant difference based on whether the visitor was a first time visitor or a returning visitor. 
Respondents were given a yes or no question pertaining to whether or not this was their first time at the White Salmon River. A t-test to compare the means of feelings of crowding between first time visitors and return visitors was used.

$R_{2 d:}$ There is no significant difference based on group type (commercial or private).

Again, this questions only gave users two options to describe their group type, thus means were compared to discover the relationship between the two variables. $R_{3}:$ Are the crowding indicator variables effective predictors of crowding levels?

Using the evaluative standards, a multiple regression test was preformed to create a model and discover the relationship between the possible predictors and feelings of crowding. Beta scores, levels of significance and percent of variance were reported in order to illustrate the hypothesized relationship, as well as the significance of the relationships. Pearsons $\mathrm{R}$ correlations were preformed to analyze the relationship between each of the evaluative standards and the others.

$R_{4}:$ Are crowding and crowding indicators effective predictors of overall trip satisfaction?

Crowding indicators and crowding scores were analyzed against overall trip satisfaction using multiple regression tests. Beta scores and percent of variance were reported and examined, as well as levels of significance. Pearsons R correlations were also reported. While this question is similar to the above, it was used to analyze the relationship between both the feelings of crowding scores and predictors of crowding against overall visitor experience scores. 


\section{CHAPTER 4}

\section{RESULTS}

The results of the data analysis are addressed in five main sections of this chapter. The first section presents a description of the recreationist's basic demographic profile and information related to trip characteristics gathered from the White Salmon River surveys. Section two and three answer the research questions "what is the overall crowding level for the White Salmon River" and "what is the overall trip satisfaction level for the White Salmon River?" These sections also compare demographic findings with crowding and satisfaction levels reported during the survey period. The fourth section discusses which crowding indicator variables are the most suitable predictors of crowding levels. The final section of this chapter analyzed crowding levels and crowding indicators as predictors of overall satisfaction levels for the White Salmon River boaters.

\section{Research Questions}

The data collected throughout the summer season provided insight into perceived crowding levels and overall trip experiences of those who were interviewed on the White Salmon River in Washington. This section displays socio-demographic analysis of statistical differences in crowding levels and overall trip experience as well as variables that have been found to significantly affect those reported levels

\section{$R_{1}$ : What does the sample of recreationists look like?}

The respondents in this survey were asked several socio-demographic and descriptive questions such as, gender, age, group type, trip type, United States or international visitor, whether this was their first visit, and group size (table 2$)$. Respondents $(\mathrm{N}=1065)$ are defined as 
anyone who participated in a whitewater trip or excursion on the surveyed section of the White Salmon River in Washington between June 6, 2009 to September 13, 2009. Respondents had to exit the river at one of the three monitored river exiting points; BZ Corner, Husum, or Buck Creek.

Respondents were asked to rate their overall trip experience on a 1-6 scale where one equaled poor and six was a perfect trip. There were no respondents who reported overall satisfaction to be either poor $(0 \%)$ or fair $(0 \%)$. About two-thirds of respondents $(65.6 \%)$ reported a perfect rating, and $28.3 \%$ indicated their trip was excellent. Only $6 \%$ of respondents reported satisfaction levels of 4 (very good) or lower. The mean score for overall satisfaction was 5.6, meaning that respondents on average considered their trip to be between excellent and perfect (table 3).

Table 2

Socio-demographics and trip characteristics

\begin{tabular}{lcc}
\hline Age & Frequency & Valid Percent \\
\hline 30 and younger & 351 & 34.8 \\
$31-40$ & 271 & 26.8 \\
$41-50$ & 219 & 21.7 \\
51 and older & 169 & 16.7 \\
30 and younger & 351 & 34.8 \\
\hline
\end{tabular}

Gender

Male 553 55.2

Female 448 44.8

\section{First Visit}

Yes

616 59.3

No

422

40.7 


\section{Trip Type}

\begin{tabular}{lll} 
Day & 657 & 65.5 \\
Overnight & 346 & 34.5 \\
\hline
\end{tabular}

International Visitor

\begin{tabular}{ccc} 
Yes & 37 & 3.7 \\
No & 969 & 96.3 \\
\hline
\end{tabular}

\section{Group Type}

\begin{tabular}{lll} 
Commercial (Outfitter) & 746 & 70.4 \\
Private & 314 & 29.6 \\
\hline
\end{tabular}

\section{Group Size}

$\begin{array}{lcc}\text { 1-5 people } & 135 & 47.4 \\ \text { 6-15 people } & 108 & 37.9 \\ \text { 16-25 people } & 23 & 8.1 \\ \text { 26 and higher } & 19 & 6.7\end{array}$

Table 3

Overall trip satisfaction

\begin{tabular}{lcc}
\hline & Frequency & Valid Percent \\
\hline 1-Poor & 0 & 0 \\
2-Fair & 0 & 0 \\
3-Good & 9 & .8 \\
4-Very Good & 55 & 5.2 \\
5-Excellent & 300 & 28.3 \\
6-Perfect & 695 & 65.6 \\
\hline \multirow{2}{*}{ Overall Mean } & 5.6 & \\
\hline
\end{tabular}

The majority of whitewater respondents were male (55.2\%) and less than half were female (44.8\%). Over one-third of the respondents (34.8\%) fell into the 30 and younger age 
category, while the age $31-40$ accounted for $26.8 \%$ of the respondents. Those aged 41-50 accounted for $21.7 \%$. The smallest age category was 51 and older accounting for $16.7 \%$ of respondents.

Respondents were asked if this was their first visit to the White Salmon River. Over half $(59.3 \%)$ reported that it was their first visit, while the remainder $(40.7 \%)$ denoted that it was not. Respondents were also asked whether they have a U.S. zip code $(96.3 \%)$ or if they were an international visitor $(3.7 \%)$.

The survey also asked the respondents to indicate a few characteristics about their trip on the White Salmon River. The majority of respondents $(70.4 \%)$ indicated that they recreated on the river with a commercial outfitter or group. Just under one-third (29.6\%) reported that they were a private boater. Respondents were asked to specify what size group they were recreating with on the river. Just under half (47.4\%) reported they boated with $1-5$ people, $37.9 \%$ indicated that they recreated with 6-15 people, and a small proportion reported recreating with 16-25 people $(8.1 \%)$ and 26 and higher (6.7\%). Finally, respondents were asked whether they were on an overnight or a day trip. About two-thirds of respondents $(65.5 \%)$ were on a day trip, while just over one-third (34.5\%) were staying overnight in the area.

\section{$R_{2}$ : What is the crowding level on the White Salmon River?}

This research question aims to address several relationships between crowding levels and demographics. It begins with a frequency analysis, descriptive statistics and reports valid percents for overall crowding on a 9-point scale. The second part of the analysis seeks to address three null hypotheses that relate socio-demographic questions to crowding level scores:

$R_{2 A}$ There is no significant difference based on gender.

$\mathrm{R}_{2 \mathrm{~B} \text { : }}$ There is no significant difference based on age. 
$\mathrm{R}_{2 \mathrm{C} \text { : }}$ There is no significant difference based on whether the visitor was a first time visitor or a returning visitor.

$\mathrm{R}_{2 \mathrm{~d} \text { : }}$ There is no significant difference based on group type (Commercial or Private).

\section{Measuring Crowding Levels}

Respondents were asked to indicate, on a 9-point scale, to what extent they felt crowded while on the river. The scale is listed horizontally with descriptive words underlining each number as follows; 0-2 not at all crowded, 3-4 slightly crowded, 5-7 moderately crowded and 89 being extremely crowded. As indicated, the majority of respondents (58.8\%) reported being 'not at all crowded,' while $25.2 \%$ reported being 'slightly crowded,' and only $16.1 \%$ reported a crowding level of 5 (moderately crowded) or higher. The mean crowding level for survey respondents was 2.64 which is between 'not at all crowded' and "slightly crowded".

Part A of research question two analyzed the relationship between crowding scores and gender. A comparison of means was preformed to analyze the difference between crowding levels of males and females. Males reported a higher overall mean crowding score (2.75) than females (2.51) with the mean for both groups combined (2.64).

Part B of question two tested the hypothesis that there is no significant difference in crowding scores based on age. Respondents were asked to indicate their age range on the survey Table 4 Feelings of crowding (1-9 scale).

\begin{tabular}{lccccccccccc}
\hline & & Not at Crowded & \multicolumn{2}{c}{ Slightly Crowded } & \multicolumn{2}{c}{ Moderately Crowded } & \multicolumn{2}{c}{ Extremely Crowded } \\
\hline $\begin{array}{l}\text { Crowding } \\
\text { Score }\end{array}$ & 0 & 1 & 2 & 3 & 4 & 5 & 6 & 7 & 8 & 9 \\
\hline $\mathrm{N}$ & 1 & 352 & 272 & 161 & 107 & 66 & 72 & 25 & 4 & 4 \\
$\begin{array}{l}\text { Valid } \\
\text { Percent }\end{array}$ & .1 & 33.1 & 5.6 & 15.1 & 10.1 & 6.2 & 6.8 & 2.3 & .4 & .4 \\
\hline
\end{tabular}


instrument. The highest crowding mean score (2.71) was reported by respondents who were 30 years and younger, while the lowest mean score (2.35) was reported by those 51 and older. Respondents in the 31-40 years (2.70) category were next, followed by $41-50$ years (2.65). A One-way Anova test was conducted with results indicating no significant differences based on age. This finding confirmed the null hypothesis.

Next, it was hypothesized that there was no significant difference based on whether it was the visitors first time at the White Salmon River or the respondent was a return visitor. The mean scores were compared, showing that the mean for first time visitors was lower (2.50) than those who were return visitors (2.84), with the overall mean for both groups being 2.64. This rejected the hypothesis that there is no significant difference based on first time or return visitor status.

The final question tested whether there was a difference in crowding scores based on the type of group a visitor traveled with. There were two groups for users to choose from: 1) Commercial outfitter, 2) Private (no outfitter). The ratio of commercial to private boaters for those surveyed was about 70-30. Those who traveled with a commercial group (2.56) reported a lower overall mean score than those who travel the river privately (2.84). The mean for both groups was 2.64. There is a difference based on group type when it comes to overall feelings of crowding on the White Salmon. 
Table 5.

Feelings of crowding for independent variables

\begin{tabular}{lcc}
\hline Independent Variables & $\mathrm{N}$ & Mean \\
\hline Gender & & \\
Male & 553 & 2.75 \\
Female & 448 & 2.51 \\
Total & 1001 & 2.64
\end{tabular}

\section{Age Range}

30 and younger

351

2.71

$31-40$

271

2.70

41-50

219

2.65

51 and older

169

2.38

Total

1010

2.64

First Visit?

Yes

No

Total

Visitor Type

Commercial

Private

Total
746

2.56

314

2.84

616

2.50

422

2.84

1038

1060

Table 6.

Results of the Anova Table for feelings of crowding Independent Dependent Variable Variable

Feelings of Crowding

F Significance

Age

1.577
.193 


\section{$\mathbf{R}_{3}$ : Are the crowding indicator variables effective predictors of crowding levels?}

A multiple regression test was used to assess the strength of the relationship between crowding indicator variables with the overall feelings of crowding. During the interview and survey process, respondents were asked to answer several questions pertaining to crowding and possible indicators of crowding. These attributes included trip characteristics, expectations, wait time conflict and encounters. A total of 17 possible crowding indicators were identified and tested within a regression model. These crowding indicators were analyzed as independent variables which were regressed against feelings of crowding, the dependent variable. The analysis displayed that only six of the original 17 crowding variables were significant predictors of feelings of crowding.

Crowding indicator variables were arranged and tested in order to develop the best possible model for predictors of feelings of crowding. The most significant predictor of crowding was number of others seen (Beta .375). The second strongest predictor was percent of time in sight of others (Beta .297). These variables were followed by actual vs. expected crowding (Beta .220), group type (Beta .188), number of times ok to see others (Beta -.179) and wait time at the start in minutes (Beta .094). All other hypothesized variable did not prove to be effective predictors of feelings of crowding. The final model, which includes the six significant crowding variables, accounted for $45.7 \%$ of the variance.

A Pearsons R Correlation analysis was performed during the regression analysis in order to measure the strength of the linear relationships between the crowding indicator variables. The strongest linear relationship reported was between the number of times it is ok to see others were seen and number of others seen (.575) followed by number of others seen and percent of time others seen (.436). The strongest negative relationship was found to be between group 
type and wait time at the start (-.164). There was little correlation between wait time at the start and number of times ok to see others (-.002) and between group type and percent of time in sight of others (-.016).

Table 7

Results of multiple regression analysis of crowding variables with feelings of crowding

\begin{tabular}{lll}
\hline Indicator Variables & R & Beta \\
\hline Number of others seen & .114 & $.375^{* * *}$ \\
Percent of time in sight of others & .018 & $.297 * * *$ \\
Actual Vs. Expected Crowding & .298 & $.220 * * *$ \\
Group Type & .757 & $.188 * * *$ \\
Number of times ok to see others & -.062 & $-.179 * *$ \\
Wait time at start (Minutes) & .024 & $.094 *$ \\
& $\mathrm{R}^{2}=.457$ & $\mathrm{~F}=40.477$ \\
\hline
\end{tabular}

*Significant at .05 level, **Significant at .01 level, ***Significant at .001 level

Figure 4

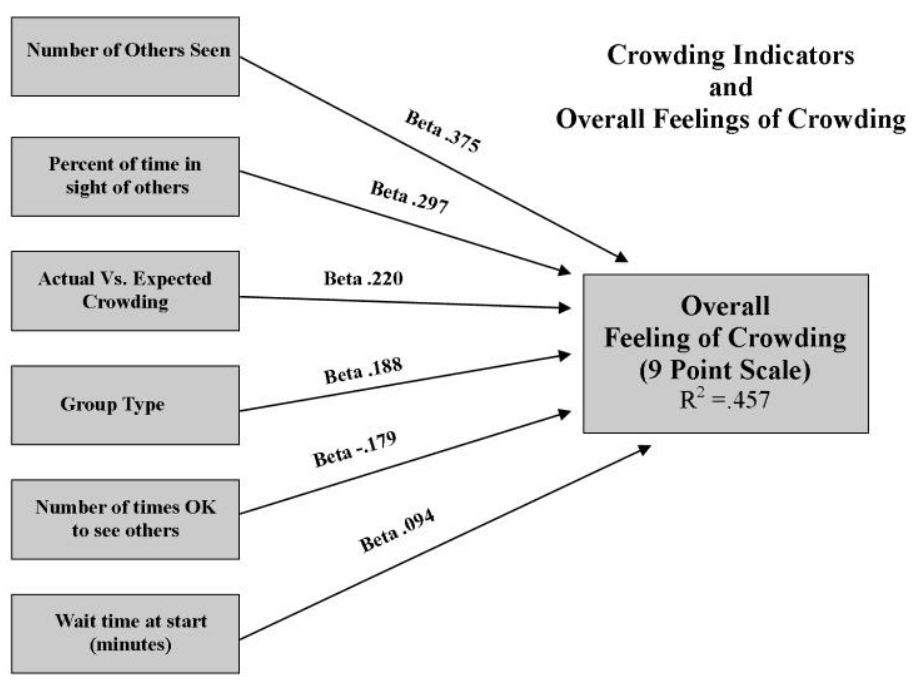


Table 8

Pearson R Correlations for crowding indicator variables

\begin{tabular}{lllllll}
\hline & $\begin{array}{l}\text { Actual } \\
\text { Vs. } \\
\text { Expected }\end{array}$ & $\begin{array}{l}\text { Percent of } \\
\text { time in sight } \\
\text { of others }\end{array}$ & $\begin{array}{l}\text { Number of } \\
\text { others Seen }\end{array}$ & $\begin{array}{l}\text { Ok to see } \\
\text { others }\end{array}$ & $\begin{array}{l}\text { Group } \\
\text { Type }\end{array}$ & $\begin{array}{l}\text { Wait } \\
\text { time }\end{array}$ \\
\hline Actual Vs. Expected & 1.00 & & & & & \\
Percent of time in sight & .380 & 1.00 & & & & \\
of others & & & & & & \\
Number of others seen & .258 & .436 & 1.00 & & & \\
Ok to see others & .104 & .164 & .575 & 1.00 & & \\
Group type & .025 & -.016 & .122 & .120 & 1.00 & \\
Wait time & .125 & .237 & .077 & -.002 & -.164 & 1.00 \\
\hline
\end{tabular}

\section{$\mathbf{R}_{4}$ : Are crowding and crowding indicators effective predictors of overall trip satisfaction?}

The final research question tested the strength of the relationship between feelings of crowding and the 17 indicator variables against overall trip satisfaction. Respondents indicated during the interview period a trip satisfaction score ranging from poor through perfect (1-6). A multiple regression analysis was used to test crowding and the indicator variables as well as attempt to create a significant model for the proposed relationship.

The regression analysis found that four of the original 17 crowding indicators as well as feelings of crowding scores were significant predictors of overall trip satisfaction (table 8). Feelings of crowding (Beta -.205) proved to be the strongest predictor of overall trip satisfaction, followed by Group Type (Beta -.141) and social conflicts (.071). The weakest predictors of overall satisfaction were 'wait time at the start' (Beta -.064), and percent of time in sight of others (Beta .070). The model accounted for only $7.3 \%$ of the variance. 
The regression analysis also produced a Pearsons R Correlation to assess the relationship between feelings of crowding and the indicator variables against overall trip satisfaction (Table 9). There were no correlations that proved to be overwhelming. The strongest positive correlation occurs between feelings of crowding and percent of time in sight of others (.382) followed by wait time at start and percent of time in sight of others (.195), wait time at the start and feelings of crowding (.167). The majority of the relationships between indicator variables were negative; though none of them were extremely significant. The strongest negative correlation was between feelings of crowding and overall trip satisfaction (-.210) followed by group type and overall trip satisfaction (-.162). These were also the strongest correlations between a possible predictors and overall trip satisfaction

Table 9

Results of multiple regression analysis of feelings of crowding and indicator variables with overall trip satisfaction.

\begin{tabular}{lll}
\hline Indicator Variables & $\mathbf{R}$ & Beta \\
\hline Feelings of crowding & -.074 & $-.205^{* * *}$ \\
Group type & -.193 & $-.141^{* * *}$ \\
Social conflicts? & .336 & $.071^{*}$ \\
Percent of time in sight of others & .001 & $.070^{*}$ \\
Wait time at start & -.005 & $-.064^{*}$ \\
& &
\end{tabular}

*Significant at .05 level, $* *$ Significant at .01 level, $* * *$ Significant at .001 level 
Table 10

Pearson Correlations for crowding indicator variables

\begin{tabular}{lllllll|}
\hline & $\begin{array}{l}\text { Overall } \\
\text { Rating }\end{array}$ & $\begin{array}{l}\text { Feelings of } \\
\text { Crowding }\end{array}$ & $\begin{array}{l}\text { Group } \\
\text { Type }\end{array}$ & $\begin{array}{l}\text { Percent } \\
\text { of time } \\
\text { in sight } \\
\text { of others }\end{array}$ & $\begin{array}{l}\text { Wait time } \\
\text { at start } \\
\text { (minutes) }\end{array}$ & $\begin{array}{l}\text { Social } \\
\text { Conflicts }\end{array}$ \\
\hline $\begin{array}{l}\text { Overall Rating } \\
\text { Feelings of }\end{array}$ & 1.00 & & & & \\
crowding & -.210 & 1.00 & & & \\
Group type & -.162 & .082 & 1.00 & & \\
$\begin{array}{l}\text { Percent of time in } \\
\text { sight of others }\end{array}$ & -.004 & .382 & -.154 & 1.00 & \\
Wait time at start & -.068 & .167 & -.143 & .195 & 1.00 & \\
(minutes) & & & & & \\
Social conflicts & .102 & -.127 & -.043 & -.055 & -.044 & 1.00 \\
\hline
\end{tabular}




\section{CHAPTER 5}

\section{DISSCUSION}

The purpose of this study was to investigate social carrying capacity by assessing crowding indicators as predictors of crowding, as well as the effect of the visitors' feelings of crowding and its indicators as predictors of overall trip satisfaction for White Salmon River users. Understanding river users and their experiences can help agencies and managers balance the need for recreational use, conservation and protection (Tarrant \& English, 1996.). Many studies have been conducted around the United States to help understand user levels and the possible impacts these rising use levels have on the user experience (Manning, 2007; Shelby \& Colvin, 1979; Shelby \& Heberlein 1986; Tarrant \& English, 1996). The results of these studies often help managers and agencies create systems or regulations to help protect visitors from social impacts such as crowding, conflicts and negative overall experiences. This study expands upon current social carrying capacity models and expands on the current research related to crowding and the river experience. This chapter reviews and discuses the five research questions addressed in this study. At the conclusions of this chapter, recommendations for future research in this area are considered.

\section{Summary of Procedures}

This study is a primary analysis of a larger study in which data were collected for a social carrying capacity assessment. The interviews and surveys for the social carrying capacity study were conducted between June 6, 2009 and September 13, 2009. During this time, a total of 1065 completed surveys were collected from users at one of the three river exit locations. This thesis

examined five research questions, with the ultimate goal of discovering what factors lead to 
feelings of crowding on the White Salmon River and the overall effect of those predictors on overall trip experience for river users. The data was analyzed using SPSS v. 16 in order to determine the results of the proposed research questions.

\section{Discussion of Research Questions}

$R_{1}:$ What does the sample of recreationists look like?

The possible sample population for this study was anyone who recreated on the White Salmon River and exited the river at one of the three specific river exit points. The actual sample of those river users are those who answered "yes" when asked to take a survey about their experience on the White Salmon River.

Over half of the surveyed river users were male (55.2\%), while $44.8 \%$ were females. Many sources have suggested that women often choose rivers with ratings of class II or lower, while men often choose rivers that are more challenging and risky (Morais, Zillifro, \& Dubrouillet, 2001). This could be why there were less females on the White Salmon River since it is considered an intermediate-advanced class III -V river. Women might be interested in a lower class of river found in another area, while men might more often come to the White Salmon River because it is considered more risky and dangerous than other rivers available during the summer months. Though the current trend is for males to participate more in adventurous kayaking and rafting, some researchers expect the number of females to increase in the coming years (Outdoor Industry Foundation, 2005; Weaver, 2001). This element of danger and risk can also be contributed to other socio-demographics such as age.

The greatest proportion of respondents (34.8\%) were 30 or younger, while the remaining age groups ranged from $16.7 \%$ for 51 and older to $31-40$ with $26.8 \%$. Those who were $41-50$ years old accounted for $21.7 \%$ of the respondents. In other words, well over half (61.6\%) of 
respondents were 40 years old or younger and only $38.4 \%$ were older than 41 years. This coincides with other research that reports the most common age for whitewater enthusiasts is 1649 years old, with the younger and middle twenties comprising of a large percentage (Cordell et al., 1999). According to Weaver (2001), those under the age of 24 are more likely to participate in whitewater boating activities then those in older generations. The class of the river may also have an effect on the age of users. Whitewater, especially higher classed whitewater, can be difficult and require a lot of physical and mental ability that younger generations seek (AWA, 2010). It could be possible that older generations perceive a higher risk in these activities or the activities require too much physical exertion. A river of a lower class rating could potentially have more kayakers of an older age than a river with a higher class rating. Research suggests that kayaking is very spread out among all age groups for flat water and class I kayaking, but narrows for whitewater boating (OIF, 2005).

Most river user respondents were recreating on the river with a commercial outfitter (70.4\%), while only $29.6 \%$ were with a private group. Almost three-quarters of respondents were on a day trip (65.5\%), leaving slightly over one-third as overnight users $(34.5 \%)$. The majority of respondents paddled the river with a group of 1-5 people (47.4\%), followed by 6-15 people $(37.9 \%), 16-25$ people $(8.1 \%)$ and 26 or more $(6.7 \%)$ Most users traveled in smaller to medium size groups and were from the United States (96.3\%) as opposed to an international location $(3.7 \%)$.

Similar to previous whitewater river research, the majority of White Salmon River users were first time river users (59.3\%). This could have an overall affect on encounters, crowding, and satisfaction, because commonly those who have not experienced the river before have no 
preconceived ideas about encounters or what to expect on their river trip (Hsu et al, 2007; Manning, 2000; 2007; Shelby \& Heberlein, 1986; Tseng et al., 2009).

For several of the socio-demographic questions the results were similar to the findings within the literature. Many studies have found that there are more commercial boaters than private boaters (Boteler 1984; Graefe et al., 1996; Shelby \& Heberlein, 1986). It is also common for users to enjoy boating in smaller groups and it is common for there to be slightly more men than women (Morais, et al., 2001; OIF, 2005; Weaver, 2001). Again, men tend to seek more challenge on whitewater whereas women pursue more moderate rivers. The White Salmon River is considered to be an intermediate to advanced river, which could possibly be too high of a rating for many women and their families (Cordell, 2008; Cordell et al., 1999). White Salmon River users could prefer small groups because it is a fairly narrow river. If users boat with larger groups and then meet up with another large group it could potentially lead to higher perceived crowding levels. Smaller groups can potentially lead to less river congestion, which in turn could allow users to feel less crowded (Manning \& Lime, 1996; Rae \& Eagle, 2007).

In summary for question 1 , the majority of respondents were male (55.2\%) and fell into the category of 30 and younger (34.8\%). Most river users were with a commercial trip (70.4\%), were experiencing the White Salmon for the first time (59.3\%) and traveled with a group between 1-5 people in size (47.4\%). Most visitors were from the United States $(96.3 \%)$ and the majority of users were on a day trip (65.5\%).

$R_{2}:$ What is the crowding level on the White Salmon River?

Frequency statistics and valid percents were used to create an understanding of perceptions of feelings of crowding for White Salmon River users. Respondents were asked to rate their feelings of crowding on a 1-9 scale, where 1 indicates no feelings of crowding and 9 is 
the most crowded. Overall respondents did not experience high or significant levels of crowding. Almost two-thirds of respondents reported being "not at all crowded" (58.8\%) having crowding scores between 0-2 on the 1-9 scale. A score of 0 was left in, even though it was not an option on the survey, to illustrate the low crowding levels found on the river. The second highest crowding score was reported as "slightly crowded" (25.2\%), scoring between 3-4, and the remainder of respondents $(16.1 \%)$ scored higher than a five. The overall mean score for users is 2.64. This indicates that respondents generally do not feel crowded while boating on the White Salmon River. The vast majority (84\%) of those surveyed indicated that they never felt more than "slightly" crowded while on the river. Feelings of crowding on one river can be different than crowding on a different river due to the uniqueness of each place and can be attributed to other indicators and predictors. Past research on the White Salmon River suggests that its distance from populated areas, short length, and the inability for more than one party to launch at a time from BZ corner, evenly distributes users resulting in a lower reported crowding rate (Brunson et al., 1992, p. 23).

$R_{2 A:}$ There is no significant difference based on gender.

Mean scores were determined in order to examine the relationship between gender and the feelings of crowding score indicated by the survey participants. The highest overall mean scores were reported by males (2.75), while the females overall mean was 2.51 on the 9-point scale. This test shows that there are differences between feelings of crowding between males and females. In other words, on the White Salmon River males reported that they were significantly less crowded, on average, than females.

$R_{2 B:}$ There is no significant difference based on age. 
A One-way Anova test was administered to find the mean scores for each specified age group and test the significance of the relationship between age and feelings of crowding. The highest mean crowding score was reported by those 30 and younger (2.71), followed by $31-40$ years (2.70), and those age 41-50 years (2.65). The lowest reported score (2.35) was reported by those 51 and older. The mean analysis shows that as the categories rise in age range, the mean crowding score goes down. The results of the one-way ANOVA test indicate there is no significant difference in feelings of crowding based on age range.

$R_{2 C:}$ There is no significant difference based on whether the visitor was a first time visitor or a returning visitor.

A compare means analysis was used to examine the significance of visitor type on the overall feelings of crowding. The results show that those who are first time visitors (2.50) have a lower mean crowding score than those who have boated the White Salmon River at a previous time (2.84), with the overall mean for both groups being 2.64. The test reported a significant relationship between visitor type and feelings of crowding. There is a difference between mean crowding scores for return and first time visitors. In other words, those who have previously paddled the White Salmon River rated their feelings of crowding higher than those who were experiencing the river for the first time.

$R_{2 d:}$ There is no significant difference based on group type (commercial or private).

A test was performed to compare the mean scores in order to discover the relationship between group types and reported crowding score. The results of the test showed that those who experienced the river with a commercial outfitter (2.56) were less crowded than those who traveled with a private group (2.84). This relationship proved there is a significant difference in 
crowding scores in relation to group type. In sum, boaters who were in private groups had a higher level of perceived crowding than guests on a commercial river trip.

$R_{4}:$ Are the crowding indicator variables (wait time, group size, and number of others seen) effective predictors of crowding levels?

A multiple regression test was used to assess the relationship between the 17 crowding predictors and overall feelings of crowding. A total of six of the 17 indicator items were significant predictors of feelings of crowding. The statistical software SPSS (version 16) was used to create a model for feelings of crowding using these six items. These items included numbers of others seen, percent of time in sight of other boats, actual vs. expected crowding, group type, number of times ok to see others and wait time at the start. Overall, the regression model created accounts for $45.7 \%$ of the variance associated with feelings of crowding. $R_{5}:$ Are crowding indicators effective predictors of overall trip satisfaction?

To analyze the relationship between possible indicators and overall trip satisfaction, a multiple regression test was preformed. Of the possible 17 variable indicators, only four were found to be significant predictors of overall trip satisfaction. These items included group type, wait time at the start, percent of time in sight of others, and social conflicts. Feelings of crowding also was found to be a significant predictor. SPSS (version 16) was used to create a model using the five predictors of overall trip satisfaction. The overall regression model accounted for $7.3 \%$ of the variance meaning that something else other than the suggested possible predictors affects the overall trip experience. 


\section{Conclusions}

The purpose of this study was to replicate and expand on several established frameworks for social carrying capacity in order to create a model that would account for a high percent of the variance associated with predictors of crowding as well as overall trip satisfaction for the White Salmon River users. This study successfully created a model for predicting crowding and overall trip satisfaction based on similar research into social carrying capacity in a whitewater setting (Boteler, 1984; Burns et al., 2008; Graefe et al., 1984; Shlelby \& Heberlein, 1986; Stankey, et al., 1985; Stankey \& McCool, 1986; Tarrant \& English, 1996).

The respondents in this study are representative of river users on the White Salmon River in Washington during the summer of 2009. The majority of respondents were first time visitors (59.3\%) and had not boated on the White Salmon River before the trip in which they were surveyed. There were more males surveyed than females, age range was split, having $62 \%$ of respondents being under 41 and around $38 \%$ being over the age of 41 . Most users traveled the river with a commercial outfitter $(70.4 \%)$. Of those who were surveyed, only $14.8 \%$ boated with groups including 15 or more people. Respondents were overwhelmingly from the United States as well as traveling to the river for a day trip.

The three hypothesized relationships between crowding and socio-demographics proved that only gender and visitor type display differences with regards to feelings of crowding scores. Women reported a lower crowding score than males. The analysis found that those who had previously boated the White Salmon River reported higher crowding scores on average than those who had not experienced the river before. This coincides with current literature on the subject that suggests that people who have pre-conceived ideas or expectations about an area can be more sensitive to crowding and higher use levels (Manning, 2007; Manning \& Lime, 1996; 
Rae \& Eagles, 2007; Shelby \& Heberlein 1986). It also compliments previous literature that suggests those who do not have past river experience can report higher satisfaction levels because they do not already have experience with how many encounters to expect, what the type of setting is, or how the river trip is usually carried out (Hsu et al., 2007; Manning, 2007; Rae \& Eagle, 2007; Shelby \& Heberlein, 1986; Tseng et al., 2009)

The model created using the battery of 17 evaluative standard items upheld the hypothesized relationship, confirming a strong model for feelings of crowding. The items identified as indicators (feelings of crowding, group type, actual vs. expected, number of others seen, number of times ok to see others, and wait time at start) followed similar findings in previous research and literature about what factors contribute to perceptions of crowding by outdoor recreationists. The most significant predictor, number of others seen, can be attributed to the idea that the number of encounters one has while recreating will affect the overall perception crowding for that activity (Boteler, 1984; Manning, 2000; Manning \& Lime, 1996; Shelby \& Heberlein, 1986; Stankey et al., 1984; Tseng et al., 2009). Percent of time in sight of others and number of times ok to see others also coincide with the theory of encounters because as the percentage of time spent in sight of others rises, so do feelings of crowding for the White Salmon users (Manning, 2000, 2007; Tseng et al., 2009).

Previous literature also suggests that expectations for encounters along with what was actually experienced may affect an individual's overall feeling of crowding (Hsu et al., 2007; Manning, 2007; Manning \& Lime, 1996; Shelby \& Heberlein, 1986; Tseng et al., 2009). This study agrees with these findings. Actual versus expected crowding was found to significantly predict feelings of crowding. If someone has a pre-conceived idea about how many people they encounter or how their river experience will go, it can cause them to feel more crowded if what 
was expected is exceeded (Manning, 2007; Manning \& Lime, 1996; Shelby \& Heberlein, 1986; Tseng et al., 2009). Similarly, literature suggests that there is a high expected encounter rate for whitewater than for other adventure sports (Hsu et al., 2007). This could explain why overall crowding was low on the White Salmon River even though it is a popular whitewater river.

The model accounted for $45.7 \%$ of the variance associated with crowding, making it a strong model for evaluating feelings of crowding. Encounter evaluative standards were found to be the most significant predictors of overall feelings of crowding. The evaluative standards group type and wait time also were found to be significant in predicting the level of crowding experienced by visitors. As with other social capacity studies, the type of group that users boated the river with affected the perceived crowding levels (Manning, 2007; Manning \& Lime, 1996; Shelby \& Heberlein, 1986; Tseng et al., 2009). The model created upholds the necessary carrying capacity cause and effect relationship between use levels and impact parameters (Burns et al., 2008).

Several of the 17 items that did not satisfy the model for feelings of crowding have been found in other research to be connected to perceived crowding. These items are social conflicts and group size. This finding could be attributed to the low incidence of conflict on the White Salmon River, the low level of crowding, or the high level of satisfaction. Often higher conflict can contribute to higher perceived crowding, but there was not a high level of conflict for this river (Manning, 2007). The lack of significance of these items illustrates the difficulty and variance that occurs when examining carrying capacity in a whitewater river setting.

The final model tested the relationship between feelings of crowding and the 17 evaluate indicator items on the overall trip satisfaction. The model supports findings from previous literature indicating there is little to no significant relationship between crowding and crowding 
variables on overall satisfaction (Manning, 1996; Manning \& Lime 1996; Shelby \& Heberlein, 1986; Shelby \& Nielson, 1976; Strober, 2004). The model found only 5 significant variables; one of which was feelings of crowding and only accounted for $7.3 \%$ of the variance. This result suggest that on the White Salmon River the evaluative indicators might be related to satisfaction but do not have any significant relationship or effect on overall trip satisfaction. This could also be attributed to the high level of satisfaction on the river. Since respondents were relatively satisfied, they were not strongly affected by the evaluative standards used. These findings are similar to the literature that suggests that factors other than crowding and crowding evaluators have an effect on users' overall trip experience (Shelby \& Heberlein, 1986).

\section{Management Implications}

The findings of this study can help managers understand what affects a users experience and in turn can use this research to evaluate management decisions involving use levels and use level regulations. The model created for feelings of crowding accountant for $45.7 \%$ of the variance, which is relatively strong for a river capacity study. The most significant predictors of crowding levels for the White Salmon River were related to encounters. In fact, four of the six items found to be significant were encounter evaluative standards. Managers can use this information to address regulatory numbers and daily loads for the river. Possible launch times and trip spacing could be used to spread out boating groups in order to lessen the number of encounters per trip for users.

It should also be noted that the wait time at the start affects perceived crowding levels. Managers could use this information to assess possible launch times and spacing between outfitters and larger groups to alleviate congestion at launch areas; especially BZ Corner. Also, it is notable that group type predicts crowding. Managers should keep in mind that private and 
outfitted boaters might approach crowding differently. Private boaters tend to feel more crowded. This could be related to encounters with larger commercial trips who can take up a large amount of space on a narrow river like the White Salmon River. Scheduling specific launch times for private boaters when outfitters are not also launching may help lower crowding levels for both group types.

It is important for managers to understand that while these variables do affect perceived crowding levels, the overall feelings of crowding for the White Salmon River are relatively low. The overall mean for crowding was 2.64, which on the 9-pt crowding scale lies between 'not at all' and 'slightly' crowded. It should also be noted that only $16.1 \%$ of respondents reported being more than moderately crowded. This means that river users do not feel crowded. It should also be mentioned that river users rated their overall trip experience as a 5.6. While trip experience was not found to have a significant relationship with crowding, it is important to note that users reported low crowding and high satisfaction scores. Managers should take these findings into consideration when creating regulations or restriction for future use. Small changes could improve the situation but large changes may not be necessary since users are satisfied with the current situation. The companies functionally manage themselves with little conflict currently, so there is not an immediate need for drastic changes.

Finally, this study assists in illustrating the importance of understanding use levels and the perceptions of the users who are experiencing the river. Carrying capacity studies are used not only to protect the resource being used but also the visitors who comes to enjoy it. If the thoughts and perceptions of the resource users are ignored or neglected it could lower enjoyment for users or even cause them to pursue their sport elsewhere. Managers must be aware of the social impacts that come with the use of a river, especially a popular river such as the White 
Salmon River. If visitors become overwhelmingly impacted by social aspects of the river they might find a river elsewhere that can satisfy their needs. In a place like Washington where rivers and outdoor recreation are readily available, social impacts on the White Salmon River could mean a loss of state tourism revenue. The river's close proximity to Oregon and its major cities could easily play a role if users were displaced. Users could choose a southern or eastern destination to enjoy the whitewater of a different state, hurting the Washington tourism economy. Therefore, managers should actively monitor and study use levels and social impacts in a similar manner to ensure the satisfaction and return of its users.

\section{Recommendations for Future Research}

In the future it would be interesting to address this issue by also looking at several other possible factors that can affect crowding and overall satisfaction. This study did not take into account the class of the river. Some research suggests that the difficulty of the river can affect the type of users that boats the river (Morais et al., 2001; OIF, 2007; Weaver, 2001). If one were to research a class II river there may be different user groups than on a class III-V river such as the White Salmon River. Future research might compare the profiles of river users based on river difficulty.

Also, water flow has been found to have an effect on crowding and satisfaction (Shelby \& Heberlein, 1986). As flow changes so does the difficulty and excitement of the river. This variable might be taken into account to uncover any difference between those who experience the river at low flows and those who experience it at high flows. Similarly, and specific to the White Salmon River, is the rapid called Husum Falls. At lower flows everyone has the opportunity to run this class V waterfall, while at high flows the U.S. Forest Service does not allow users to go over the falls. This could potentially affect the excitement factor as well as 
creating a possible delay in the river trip. Those who come expecting to boat over the waterfall, but who are not given the opportunity may report different crowding and satisfaction scores than those who do run the falls. The process of going around the falls could also create a sense of crowding due to the amount of people standing on the shore lines during a portage by a large trip. It would be interesting to see if these factors had an affect on crowding levels and trip satisfaction scores.

One final issue that would be better understood with further research is the relationship between private boaters and commercial boaters. There has traditionally been a disconnect between these two groups. Often private boaters find outfitter trips to be burdensome and sometimes overwhelming. Studying this relationship and the effects that stem from it could help managers better manage for both groups of river users. This study only brushed the surface and research could seek to understand the connection at a deeper level.

Overall, crowding and social carrying capacity are complicated and can often be difficult to measure. Many studies throughout the years have found that it is not an easy task to measure and assess use levels. Future studies should seek to find information pertaining to other factors that may also have a relationship with perceived crowding and trip satisfaction. Researchers should work hard at identifying other factors within the whitewater setting that could potentially predict feelings of crowding and trip satisfaction to better manage river recreation in the future. 


\section{APPENDICES}

\section{Appendix A}

\section{Survey Instrument}

Gender M F Date:

Time:

Location

Interviewer

\section{White Salmon River Survey}

Please take a few minutes to answer these questions. We are trying to learn more about the recreational use of the White Salmon River and your impressions are important to us. All answers will be kept confidential.

1. Which type of user group did you run the river with? Commercial trip (outfitter) Private group

2. Where did you begin your trip today?

3. When you made plans to run the White Salmon, how far in advance did you make that decision?

months

weeks

days hours

4. Overall, how would you rate your trip today?

Poor

Fair, it just didn't work out very well

Good, but I wish a number of things could have been different

Very good, but it could have been better

Excellent, only minor problems

Perfect

Comments:

5. At the launch site, how long did you have to wait for other parties to leave before you could start your trip? minutes

6. How did the number of people you saw during your visit to the White Salmon River compare with what you expected to see?

A lot less than you expected

A little less than you expected

About what you expected
A little more than you expected

A lot more than you expected

You didn't have any expectations 
7. How crowded did you feel during your visit to the White Salmon River [Circle one number]

$\begin{array}{lllllllll}1 & 2 & 3 & 4 & 5 & 6 & 7 & 8 & 9\end{array}$

\begin{tabular}{llll}
\hline Not at all Crowded & Slightly Crowded & Moderately Crowded & Extremely Crowded
\end{tabular}

8. While you were on the river today, about what percent of the time were you in sight of boats from other groups? (circle a number)

\begin{tabular}{lllllllllll}
$0 \%$ & $10 \%$ & $20 \%$ & $30 \%$ & $40 \%$ & $50 \%$ & $60 \%$ & $70 \%$ & $80 \%$ & $90 \%$ & $100 \%$ \\
\hline
\end{tabular}

9. How many times did you see boats from other groups while you were on the river? If you saw the same boat more than once, count each time separately times

10. With which size group would you rather run the river?

small (5 people or less)

medium (6-15 people) large (16-25 people)

makes no difference to me

11. If you have to wait for other parties before you can start your trip, it would be O.K. to wait at the launch site as long as..... minutes it doesn't matter to me

12. While on the river, it would be O.K. to see boats from other groups...? times it doesn't matter to me

13. What would be an acceptable percentage of time to see boats from other groups while you are on the river? (circle a number)

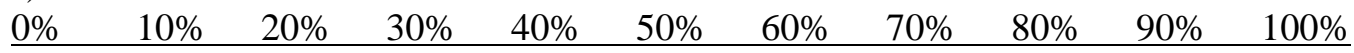

14. If you have to wait for other parties to leave before you can portage or run the falls, it would be O.K. to wait as long as..... minutes it doesn't matter to me

15. Which category best describes the experience you think should be provided on the White Salmon River? Wilderness: where solitude is part of the experience Semi-wilderness: where complete solitude is not expected Undeveloped recreation: where you expect to see other people some of the time Scenic recreation: where you expect to see other people much of the time Social recreation: where seeing many people is part of the experience

16a. During your trip, did you have any conflicts with other parties? yes no

16b. If yes, briefly describe who was involved and the nature of the conflict. 
17. Is this your first visit to the White Salmon River? Yes No

[If no] In what year did you make your first visit to the White Salmon River? year

17a. In a typical year, how many days do you spend recreating on the White Salmon River? days

17b. In a typical year, how many days do you spend recreating at other rivers besides the White Salmon River?

18. Is your trip today... an overnight visit to this area a day trip[check one]

18a. In total, how many days (or hours) long will this trip be?

_ days hours (if day trip)

\section{Question 20 Omitted for White Salmon Study}

21. What do you like MOST and LEAST about the White Salmon River?

\section{MOST}

\section{LEAST}

22. If you could ask resource managers to improve some things about the way people experience the White Salmon River, what would you ask them to do?

23. Overall, how would you rate the quality of each of the following at the White Salmon River:

\begin{tabular}{|l|c|c|c|c|c|c|}
\hline & Awful & Fair & Good & Very & Excellent & Not \\
& & & & Good & & applicable \\
\hline Health and cleanliness & 1 & 2 & 3 & 4 & 5 & NA \\
\hline Safety and security & 1 & 2 & 3 & 4 & 5 & NA \\
\hline Condition of facilities & 1 & 2 & 3 & 4 & 5 & NA \\
\hline Responsiveness of staff & 1 & 2 & 3 & 4 & 5 & NA \\
\hline Recreation setting & 1 & 2 & 3 & 4 & 5 & NA \\
\hline
\end{tabular}


24. Please look at this list of statements that address your feelings about this trip to the White Salmon River. Please indicate your level of agreement with each of the statements listed below.

\begin{tabular}{|c|c|c|c|c|c|c|}
\hline & 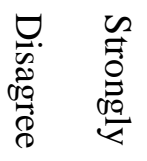 & 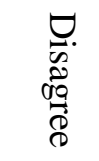 & 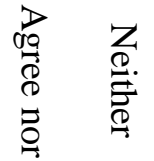 & $\underset{\substack{D \\
0}}{\stackrel{D}{0}}$ & $\underset{\substack{D \\
0 \\
0}}{D}$ & 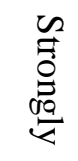 \\
\hline I thoroughly enjoyed my visit to the White Salmon River & 1 & 2 & 3 & 4 & & 5 \\
\hline I had the opportunity to recreate without feeling crowded & 1 & 2 & 3 & 4 & & 5 \\
\hline $\begin{array}{l}\text { I could find places to recreate without conflict from other } \\
\text { visitors }\end{array}$ & 1 & 2 & 3 & 4 & & 5 \\
\hline $\begin{array}{l}\text { My trip to the White Salmon River was well worth the } \\
\text { money I spent to take it }\end{array}$ & 1 & 2 & 3 & 4 & & 5 \\
\hline Recreation activities at the river were NOT compatible & 1 & 2 & 3 & 4 & & 5 \\
\hline $\begin{array}{l}\text { I was disappointed with some aspects of my visit to the } \\
\text { river }\end{array}$ & 1 & 2 & 3 & 4 & & 5 \\
\hline $\begin{array}{l}\text { I avoided some places at the river because there were too } \\
\text { many people there }\end{array}$ & 1 & 2 & 3 & 4 & & 5 \\
\hline $\begin{array}{l}\text { There is a good balance between social and biological } \\
\text { values in the management of the White Salmon River }\end{array}$ & 1 & 2 & 3 & 4 & & 5 \\
\hline The number of people at the river reduced my enjoyment & 1 & 2 & 3 & 4 & & 5 \\
\hline $\begin{array}{l}\text { The behavior of other people at the river interfered with } \\
\text { the quality of my experience [if agree, specify behavior }\end{array}$ & 1 & 2 & 3 & 4 & & 5 \\
\hline The other people at the river increased my enjoyment & 1 & 2 & 3 & 4 & & 5 \\
\hline The river and its surroundings are in good condition & 1 & 2 & 3 & 4 & & 5 \\
\hline
\end{tabular}


25. Here is a list of possible reasons why people recreate at the White Salmon River. Please tell me how important each item is to you as a reason for recreating at the White Salmon River.

\begin{tabular}{|l|c|c|c|c|c|}
\hline REASON & $\begin{array}{l}\text { Not at all } \\
\text { Important }\end{array}$ & $\begin{array}{l}\text { Somewhat } \\
\text { Important }\end{array}$ & $\begin{array}{l}\text { Moderately } \\
\text { Important }\end{array}$ & $\begin{array}{l}\text { Very } \\
\text { Important }\end{array}$ & $\begin{array}{c}\text { Extremely } \\
\text { Important }\end{array}$ \\
\hline To be outdoors & 1 & 2 & 3 & 4 & 5 \\
\hline For relaxation & 1 & 2 & 3 & 4 & 5 \\
\hline To get away from the regular & 1 & 2 & 3 & 4 & 5 \\
routine & 1 & 2 & 3 & 4 & 5 \\
\hline For the challenge or sport & 1 & 2 & 3 & 4 & 5 \\
\hline For family recreation & 1 & 2 & 3 & 4 & 5 \\
\hline For physical exercise & 1 & 2 & 3 & 4 & 5 \\
\hline To be with my friends & 1 & 2 & 3 & 4 & 5 \\
\hline To experience natural & & & & & \\
\hline surroundings & & & & & \\
\hline
\end{tabular}

26. Which of the following was the most important reason for this visit to the White Salmon River? [please check only one]

I went there because I enjoy the place itself

I went there because it's a good place to do the outdoor activities I enjoy

I went there because I wanted to spend more time with my companions

I went there because it was close to home

The last questions are about you personally and will be used only to categorize responses for different groups of visitors. Your answers are anonymous and cannot be linked to you individually. 
27. What is your home ZIP code?

28. What is your age? over 70 $16-20$ 21-30 31-40 41-50 $51-60$ $61-70$ Visitor is from another country

29. What is your gender. Male Female

30. How many people are in your group today? adults children up to 17 years

31. How many vehicles are in your group today? cars//trucks trailers (any type) 


\section{Participant Outfitters}

All Adventures Rafting

All Star Rafting

Blue Sky

River Drifters

River Riders

Wet Planet

Wildwater River Tours

Zoller's Outdoor Odyssey 


\section{References}

American Whitewater Association (1998). International scale of river difficulty. Retrieved July 8, 2010 from http://www.americanwhitewater.org/content/Wiki/safety:internation_scale _of_river_difficulty?

American Whitewater Association (2010). Safety code of American Whitewater. Retrieved July 8, 2010 from http://www.americanwhitewater.org/content/Wiki/safety:start?\#vi._ international_scale_of_river_difficulty

Boteler, F. E. (1984). Carrying capacity as a framework for managing whitewater boating use. Journal of Park and Recreation Administration, 2, 26-36.

Brunson, M., Shelby, B., \& Johnson, R. L. (1992). Current use and potential impacts of whitewater recreation in Oregon. Corvallis: Oregon State University.

Buckley, R. (2007) Adventure tourism products: Price, duration, size, skill, remoteness. Tourism Management, 28, 1428-1433

Burns, R., Graefe, A., \& Wade, J. (2008). Addressing US Forest Service recreational outfitter/guide permit policy changes. Powerpoint presented in research methods lecture, Morgantown, WV.

Cordell, K. H. (2008). The latest on trends in nature-based outdoor recreation. Forest History Today, Spring, 2008.

Cordell, K. H., Mcdonald, B. L., Teasley, J. R., Bergstrom, J. C., Martin, J., Bason, J., et al. (1999). Outdoor recreation participation trends. In K. H. Cordell (Ed.), Outdoor Recreation in American life: National assessment of demand and supply trends (pp. 219319). Urbana, IL: Sagamore Publishing.

Ewert, A.W. (2000, September). Outdoor adventure recreation and public land management: Current status and emerging trends. Paper presented at the Tenth Annual World Congress on Adventure Travel and Ecotourism, Anchorage, AK.

Ewert A. W. (2001). Trends in adventure recreation: Programs, experiences, and issues. Proceedings of the 5th Outdoor Recreation and Tourism Trends Symposium, 327-335.

Gelo, O., Braakmann, D., \& Benetka, G. (2008). Quantitative and qualitative research: Beyond the debate. Integrative Psych. Behav. , 42, 266-290.

Graefe, A. R., Gitelson, R. J., Fedler, A. J., \& Zeigler, J. F. (1989). Youghiogheny River 
recreational capacity study; Final report. Annapolis, MD: Capital Programs Administration.

Manning, R. E. (2000). Defining and establishing indicators and standards of quality. In Fulton, C., Nelson, C., Anderson, and Lime, D (Eds.), Human dimensions of natural resource management: Emerging issues and practical applications. (pp. 30-39). St. Paul: University of Minnesota.

Manning, R. E. (1997). Social carrying capacity of parks and outdoor recreation areas. Parks and Recreation, 32(10), 32-38.

Manning, R. (1999). From normative standards tos of quality: theoretical and methodogical issues. In Crowding and Carrying Capacity in Oudoor Recreation (pp. 323-334). State College, PA: Venture Publishing.

Manning, R.E. (2007). Parks and carrying capacity: commons without tragedy. Retrieved July 1, 2010 from West Virginia University. Mountainlynx Library Web site: http://site.ebrary.com.www.libproxy.wvu.edu/lib/nwvu/docDetail.action?docID=10209 875.

Manning, R. E., \& Lawson, S. R. (2002). Carrying capacity as Informed Judgement. Environmental Management , 30,157-168.

Manning, Robert E., Valliere, W. A., Wang, B., Minteer, B. A., \& Jacobi, C., (2000). Crowding in parks and outdoor recreation: A theoretical, empirical, and managerial analysis. Journal of Park and Recreation Administration, 18(2), 57-72.

Manning, R. E., \& Lime, D. (1996). Corwding and carrying capacity in the National Park System: Toward a social science research agenda. In D.W. Lime (Ed.), Crowding and Congestion in the National Parks System: Guidelines for management and research, (pp. 27-57).St. Paul, MN: University of Minnesota.

Manning, R., \& Lime, D. (2001). Visitor experience and resource protection: A framework for managing the carrying capacity of National Parks. Jornal of Park and Recreation Administration , 19 (1), 93-108.

Manning, R. E. \& O'Dell, I. (1997). Social carrying capacity of parks and outdoor recreation areas. Journal of Parks and Recreation, 32, 32-39.

Manning, R.E., Wang, B., Valliere, W., Lawson, S., \& Newman, P. (2002). Research to estimate and manage carrying capacity of a tourist attraction: A study of Alcatraz Island. Journal of Sustainable Tourism, 10 (5), 388-404.

McCool, S. F. (1996, August). Limits of Acceptable Change: A framework for managing national protected areas: Expieriences from the United States. Workshop on impact management in marine parks, 1-15. 
McCool, S. F., \& Cole, D. (1997) Experiencing Limits of Acceptable Change: Some thoughts after A decade of implementation. Limits of Acceptable Change (pp. 72-78). Ogden: U.S. Department of Agriculture.

Morais, D. B., Zillifro, T., \& Dubrouillet, S. (2001). Toward an understanding of gender differences with respect to whitewater rafting preferences. In S. Todd (Ed.), Proceedings of the 2001 Northeastern Recreation Research Symposium (pp. 299-304). Newtown Square, PA: U.S. Department of Agriculture.

Outdoor Industry Foundation (2005). Outdoor recreation participation study. Boulder, CO...Leisure Trends.

Shelby, B., \& Heberlein, T. A. (1986). Carrying capacity in recreation settings. Corvallis, OR: Oregon State University Press.

Shelby, B., \& Nielson, J. M. (1976). Use levels and crowding in the Grand Canyon. Final Report 3. Colorado: National Park Service

Shelby, B., \& Whittaker, D. (2008). Visitor capacities on rivers concepts and case studies. Yosemite Capacity Symposium v3 (pp. 1-17). Yosemite: National Park Service.

Stankey, G. H., \& McCool, S. F. (1984). Carrying capacity in recreation settings. Leisure Sciences , 6 (4), 453-473.

Stankey, G. H., McCool, S. F., \& Stokes, F. (1984). Limits of acceptable change: A new framework for managing the Bob Marshall Wilderness. Western Wildlands, 10 (3), 33-37.

Stankey, G., \& McCool, S. (1984). Carrying capacity in recreational settings: Evolution, appraisal and application. Leisure Science. 6 (4), 453-473.

Sterl, P., Wagner, S., \& Arnberger, A. (2004). Social carrying capacity of canoeists in Austria's Danube Floodplains National Park. In Sievänen, J., et al. (Eds.). Policies, methods and tools for visitor management: Proceedings of the second international conference on monitoring and management of Visitor flows in recreational and protected areas. (pp. 261-268) Vienna, Austria: Institute for Landscape Development, Recreation and Conservation Planning..

Strother, J.A., \& Vogelsong, H. (2003). Carrying capacity and visitor experience: Cape Hatteras National Seashore. In R. Shuster (Ed.), Proceedings of the 2002 Northeastern Recreation Research Symposium., (pp. 229-233). Newtown Square, PA: Department of Agriculture.

Tarrant \& English, M. A. \& English, D. (1996). A Crowding-based model of social carrying capacity: Application for whitewater boating use. Journal of Leisure Research, 28(3). 155-169. 
Tseng, Y.P., Kyle, G.E., Shafer, S., Graefe, A.R., Bradle, T.A., \& Schuett, A. (2009). Exploring the crowding-satisfaction relationship in recreational boating. Environmental Management. 43, 496-507

U.S. Department of Agriculture.(1985). The Limits of Acceptable Change (LAC) system for wilderness planning (General Technical Report INT -176) Ogden, UT: Stankey, G. H., Cole,D.N., Lucas,R. C., Peterson, M.E. \& Frissell, S.S.

Wager, J.A. (1964). The Carrying capacity of wild lands for recreation. Monograph of Forest Science, 7(23).

Water Resources Research Institue (1979, July). Determining use levels for the Rogue River (Final Report WRRI-63). Corvallis, Oregon: Shelby, B., \& Colvin, R. B.

Weaver, D.B. (ed.). (2001). The Encyclopedia of Ecotourism. Wallingford: CABI Pub.

Whisman, S. A. (1998). Limits of Acceptable Change river management annual report. A summary of LAC indicators for commercial rafting use of West Virginia rivers. Morgantown: West Virginia University. 